\title{
Hybrid Three-Phase Rectifiers with Active Power Factor Correction: A Systematic Review
}

\author{
José Teixeira Gonçalves ${ }^{1, *}$, Stanimir Valtchev ${ }^{1}$, Rui Melicio ${ }^{2,3}$, Alcides Gonçalves ${ }^{1}$ and Frede Blaabjerg ${ }^{4}$ \\ 1 Departamento de Engenharia Eletrotécnica e de Computadores, CTS/UNINOVA, FCT, Universidade \\ NOVA de Lisboa, FCT Campus Caparica, 2829-516 Monte Caparica, Portugal; ssv@fct.unl.pt (S.V.); \\ at.goncalves@campus.fct.unl.pt (A.G.) \\ 2 Instituto de Engenharia Mecânica (IDMEC), Instituto Superior Técnico, Universidade de Lisboa, Av. \\ Rovisco Pais 1, 1049-001 Lisboa, Portugal \\ 3 Instituto de Ciências da Terra (ICT), Universidade de Évora, Rua Romão Ramalho 59, \\ 7002-554 Évora, Portugal; ruimelicio@gmail.com \\ 4 Department of Energy Technology, University of Aalborg, Pontoppidanstræde 111, \\ 9220 Aalborg Øst, Denmark; fbl@et.aau.dk \\ * Correspondence: jt.goncalves@campus.fct.unl.pt
}

Citation: Gonçalves, J.T.; Valtchev, S.; Melicio, R.; Gonçalves, A.; Blaabjerg, F. Hybrid Three-Phase Rectifiers with Active Power Factor Correction: A Systematic Review. Electronics 2021, 10, 1520. https://doi.org/10.3390/ electronics10131520

Academic Editor: Carlos Andrés García-Vázquez

Received: 25 May 2021

Accepted: 18 June 2021

Published: 23 June 2021

Publisher's Note: MDPI stays neutral with regard to jurisdictional claims in published maps and institutional affiliations.

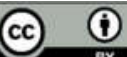

Copyright: (C) 2021 by the authors. Licensee MDPI, Basel, Switzerland. This article is an open access article distributed under the terms and conditions of the Creative Commons Attribution (CC BY) license (http://creativecommons.org/licenses /by/4.0/).

\begin{abstract}
The hybrid three-phase rectifiers (HTR) consist of parallel associations of two rectifiers (rectifier 1 and rectifier 2), each one of them with a distinct operation, while the sum of their input currents forms a sinusoidal or multilevel waveform. In general, rectifier 1 is a GRAETZ (full bridge) (can be combined with a BOOST converter) and rectifier 2 is combined with a DC-DC converter. In this HTR contest, this paper is intended to answer some important questions about those hybrid rectifiers. To obtain the correct answers, the study is conducted as an analysis of a systematic literature review. Thus, a search was carried out in the databases, mostly IEEE and IET, and 34 papers were selected as the best corresponding to the HTR theme. It is observed that the preferred form of power distribution in unidirectional hybrid three-phase rectifiers (UHTR) is $55 \% P_{o}$ (rectifier 1) and $45 \% P_{o}$ (rectifier 2). For the bidirectional hybrid three-phase rectifiers (BHTR), rectifier 1 preferably takes $90 \%$ of $P_{o}$ and $10 \%$ of $P_{o}$ is processed by rectifier 2 . It is also observed that the UHTR that employ the single-ended primary-inductor converter (SEPIC) or VIENNA converter topologies in rectifier 2 can present sinusoidal input currents with low total harmonic distortion (THD) and high Power Factor (PF), even successfully complying with the international standards. The same can be said about the rectifier that employs a pulse-width (PWM) converter of BOOST topology in rectifier 2. In short, the HTR are interesting because they allow using the GRAETZ full bridge topology in rectifier 1, thus taking advantage of its characteristics, being simple, robust, and reliable. At the same time, the advantages of rectifier 2, i.e., high PF and low THD, are well used. In addition, this article also points out the future direction of research that is still unexplored in the literature, thus giving opportunities for future innovation.
\end{abstract}

Keywords: hybrid three-phase rectifier (HTR); EV battery charging; unidirectional rectifier; bidirectional rectifier; BOOST; SEPIC; VIENNA; delta-switch; star-switch; PWM BOOST; power factor; systematic review

\section{Introduction}

The use of alternating current (AC) electricity as a standard in electrical networks was practically established through the competition known as the "war of currents", where Nikola Tesla and George Westinghouse defended the use of AC, and their opponent Thomas Edison advocated the use of direct current (DC) in the 19th century. Nikola Tesla's electric power in AC won the "war of currents" for several reasons, the most notable being the possibility of generating large amounts of electric energy and 
allowing the transport of electric power over great distances at a financial cost more viable and efficient than the DC system [1]. Nowadays, this AC power system has become the standard. Since the electrical network is given in $\mathrm{AC}$, and most charges use electrical energy in DC, such as TVs, computers, radios, electric vehicles, etc., an AC-DC rectifier is incorporated into the loads $[2,3]$.

In principle, $\mathrm{AC}$ rectification systems in $\mathrm{DC}$ were only possible with electromechanical converters. Electromechanical converters consist of an AC motor coupled to the shaft of a DC generator. This has the disadvantage of being an expensive, bulky, heavy, and noisy system. Subsequently, the studies and developments of mercury converters emerged, which remained until the end of 1950, which were surpassed by the invention of the semiconductor component [4]. Depending on technological development, solid-state electronic devices appeared in Bell Telephone's laboratories. However, it was only in 1960 that the first diode rectifier capable of rectifying a current of $100 \mathrm{kA}$ was commercially launched. Afterwards, thyristor rectifiers also appeared with the capacity to rectify currents of the order of $100 \mathrm{kA}[2,4]$.

With the invention of these semiconductor elements, the development of technology has made great strides. Currently, it is already possible to build rectifier plants that will work with currents above $350 \mathrm{kA}$. Of course, these semiconductor elements are not ideal; they have some disadvantages such as thermal losses. Thermal losses cause high heating and can cause the device to burn, but this can be solved by using heat sinks with forced cooling (cooling by deionized water or ventilated air), and water cooling is for high-power converters [2-4].

Another concern concerns the disturbances injected into the electrical network, since these switching elements (diodes, MOSFETs, IGBTs, etc.) are used in converters (rectifiers and inverters) and active loads, which are activated by the frequency of the electrical network (diode rectifiers) or through a control, thus giving rise to the injection of harmonics into the electrical network. To mitigate the disturbances that converters or loads can cause in the electrical network, standards have been imposed by energy concessionaires as a measure to safeguard the quality of energy in the electrical network. Examples of well-established and internationally known standards used on energy quality are IEC61000-3-2 and IEC61000-3-4, and in relation to the total harmonic distortion (THD) of the current injected into the electrical network, it used IEEE Std 519-2014. With this, the challenge today is to develop a system of medium or high-power converters that are even more efficient and reliable, as is the case with three-phase rectifiers [2-4].

Currently, there are several types of three-phase rectifiers with reduced harmonic content connected in several loads, which can be classified into two large groups, the bidirectional and unidirectional. In the case of unidirectional rectifiers, they use the diodes as a switching device, being activated by the frequency of the electrical energy that is applied, as is the case of the GRAETZ bridge rectifier. These rectifiers present the problem of high total harmonic distortion (THD). Bidirectional rectifiers, on the other hand, use switching devices (MOSFETs, IGBTs, etc.) activated by means of a control system [2,3]. These rectifiers can achieve good results such as low THD and high Power Factor (PF), and they can even meet international standards. These rectifiers present the problem of complexity (due to the control system) and economic viability when applied at high powers.

Some power factor correction techniques have been developed to reduce the harmonic content of some three-phase rectifiers. Figure 1 shows the classification of threephase rectifiers with reduced harmonic content. These three-phase rectifiers can show improvements in THD and PF, and some rectifiers can meet the standards of established international norms, as is the case of the hybrid three-phase rectifiers (HTR) that are part of the scope of study in this paper. 


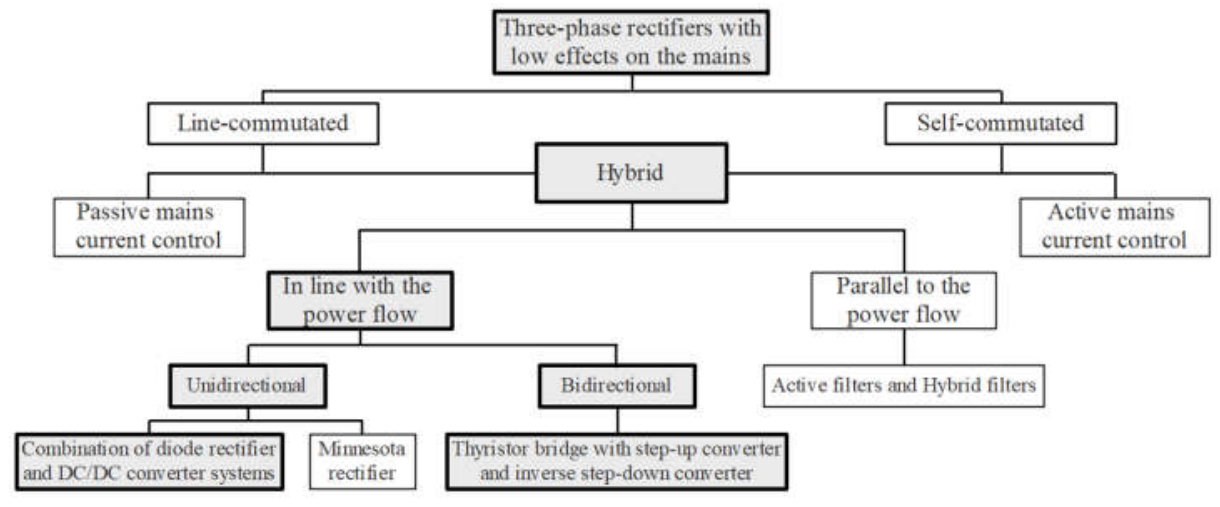

Figure 1. Classification of three-phase rectifiers with reduced harmonic content.

\section{Scope and Objective of the Study}

In Figure 1, a classification of three-phase rectifier systems for low and medium power is illustrated [5]. The focus of this work is related to the HTR in line with the power flow. These rectifiers (in line with the power flow) can be classified as unidirectional hybrid three-phase rectifiers (UHTR) and bidirectional hybrid three-phase rectifiers (BHTR), as shown in Figure 1 [5].

The HTR studied in this work can be analyzed as rectifiers with series or parallel connection between two (usually rectifier 1 and rectifier 2) or more rectifiers. Rectifier 1 is switched by the line, and in some cases, it can be connected in series with a DC converter to control the output voltage; it must also be designed in such a way that it processes the largest possible portion of the total energy delivered to the load. Rectifier 2, on the other hand, can be auto switched (controlling the output voltage) or even switched over the line, but connected without series with a DC converter to control the output voltage and carry out the active power factor correction, processing the remaining portion of the total energy delivered to the load. In addition, the rectifiers must process different current waveforms in such a way that their union reaches the desired for the source (sinusoidal or multilevel) and the load $[2,6]$.

In this case, the Minnesota rectifiers, and the rectifiers in parallel to the energy flow (rectifiers with active filters and hybrid filters) will not be studied in this paper, since their principles of operation are different. These rectifiers work in conjunction with a stage that is of the active filter type and is a device that allows the elimination of harmonics from equipment operating with non-linear loads; however, it basically processes reactive energy with no active power supply for the load [7].

In the case of the HTR studied in this paper, a great variety is found in the literature, because they can be classified or composed of several types of rectifiers and converters, such as the VIENNA rectifier, rectifier with BOOST converter, single-ended primaryinductor converter (SEPIC), etc. Therefore, to improve the studies of HTR, this systematic literature review paper has the following main objectives:

- Briefly and systematically present the existing work in relation to HTR technology;

- Identify gaps in the current state of the art of HTR, to suggest additional research;

- $\quad$ Provide the basis for new HTR research activities;

- $\quad$ Organize the HTR contents.

This paper is organized in such a way that the applied methodology is described in Section 2 and the analyses are presented in Section 3, where the six main research questions are answered. Next, the discussion is presented in Section 4, and finally, the conclusions in Section 5 are presented. 


\section{Methods}

The main objective of this paper is to collect content, analyze, and systematically summarize the types of three-phase hybrid rectifiers (HTR) with active power factor correction that exist in the literature. In this context, this study is categorized as a secondary study. The methodology used in this systematic review is based on the methodology proposed in $[8,9]$.

\subsection{Research Questions (RQ)}

The questions are designed to meet the objectives of this systematic review, which are extremely important within the review of three-phase hybrid rectifiers and thus lead this study to an appropriate and necessary line of thought. The relevant questions for this review study are as follows:

1. RQ1: In what period were the HTR published?

2. RQ2: Who are the main actors in HTR?

3. RQ3: What types of HTR are there in the literature?

4. RQ4: What types of control are most used in HTR?

5. RQ5: What types of HTR comply with international standards regarding the quality of energy in the electrical networks?

6. RQ6: What type of loads are HTR applied to?

\subsection{Search}

The systematic review was based on the search for scientific documents that demonstrate studies on HTR. The period of research of the documents had as reference (starting) the first HTR proposed in the literature in 1999 [10], which means that the HTR from 1999 to 2020 existing in the literature are studied. The year 2021 was not considered because, to date, there have been no publications on HTR. For searches of scientific documents, the following two databases were used: IEEE Xplore and the IET Digital Library.

\section{Search Terms}

To obtain most of the relevant work in the literature on hybrid three-phase rectifiers with active correction of the power factor, some search terms were developed. These search terms were designed to include most studies of unidirectional and bidirectional three-phase hybrid rectifiers, as well as multilevel and multipulse hybrid three-phase rectifiers, so it was possible to obtain the correct search terms and combine them to use in abstracts and titles of studies in the databases. Table 1 shows the strings executed in the two selected databases. With the execution of these strings, 153 articles were generated and are distributed in the respective databases according to Table 2.

Table 1. String used in databases.

\begin{tabular}{cc}
\hline Database & Search Terms \\
\hline & ("All Metadata": "Hybrid Three-Phase") OR ("All Metadata": \\
& "Hybrid Rectifiers") OR (“All Metadata": "Hybrid Rectifier") OR \\
IEEE Xplore & ("Document Title": "Hybrid Unidirectional") OR (“Document \\
& Title": “Three-Phase Unidirectional”) OR ("Document Title": \\
& "Hybrid Multilevel Power") OR ("Document Title": “Hybrid \\
& Multipulse ") \\
\hline IET Digital Library & "Hybrid Rectifiers" OR "Hybrid VIENNA rectifier \\
\hline
\end{tabular}


Table 2. Results of search queries in the databases.

\begin{tabular}{ccc}
\hline Query & Results from Query & Date \\
\hline IEEE Xplore & 131 & 28 April 2021 \\
IET Digital Library & 22 & 29 April 2021 \\
\hline
\end{tabular}

\subsection{Criteria}

To select the studies considered suitable for this review, within the set of studies resulting from the consultations (153 articles), exclusion and inclusion criteria were thus elaborated, as mentioned in Section 2.3.1 and 2.3.2, consecutively. After these criteria were executed, 34 papers were selected, which in turn are applied to the data extraction phase.

\subsubsection{Exclusion Criteria}

- $\quad$ Studies not related to HTR.

- $\quad$ Studies related to single-phase hybrid rectifiers.

- $\quad$ Studies related to Minnesota rectifiers.

- $\quad$ Studies related to three-phase rectifiers with active filters and hybrid filters.

- Studies related to three-phase rectifiers without active correction of the power factor.

2.3.2. Inclusion Criteria

- $\quad$ Studies related to HTR.

- $\quad$ Studies related to the application of HTR.

- $\quad$ Studies that describe the principle of operation of the HTR.

- $\quad$ Studies that describe the control methodology applied to the HTR.

- $\quad$ Studies that describe the design or dimensioning of HTR.

- $\quad$ Studies that describe the power distribution in the HTR.

\subsection{Data Extraction Method}

The information extracted from the literature review to answer the RQs was submitted to an analysis procedure organized as follows:

1. The number of HTR published per year and their publication channels (addressing RQ1 and analyzed in Section 3.1).

2. Name of the authors and their affiliations as well as the paper number (addressing RQ2 and analyzed in Section 3.1).

3. Describe the operation of the HTR (addressing RQ3 and analyzed in Section 3.2).

4. Describe the name of the HTR (addressing RQ3 and analyzed in Section 3.2).

5. Present the design of the HTR (addressing RQ3 and analyzed in Section 3.2.2).

6. Describe the control strategy applied (addressing RQ4 and analyzed in Section 3.3).

7. Mention the type of integrated circuit applied in the control (addressing RQ4 and analyzed in Section 3.3).

8. Mention the PF and THD obtained in the types of HTR, as well as the power distribution (addressing RQ5 and analyzed in Section 3.4).

9. Describe the type of application of the HTR (addressing RQ6 and analyzed in Section 3.5).

\section{Analysis}

This section analyzes and describes the findings related to the literature review of the 34 selected articles to answer the six questions presented in Section 2.1, which are organized in sections, as also indicated in Section 2.4.

A summary of how the 34 papers were selected for data extraction is presented in a flow diagram of the systematic review, the so called "Preferred Reporting Items for Systematic Reviews and Meta-Analyses" known shortly as PRISMA. The diagram is illustrated in Figure 2. It shows the three major phases of the process, with the 
identification of papers in the selected databases, the readability of the papers, and lastly the selected papers.

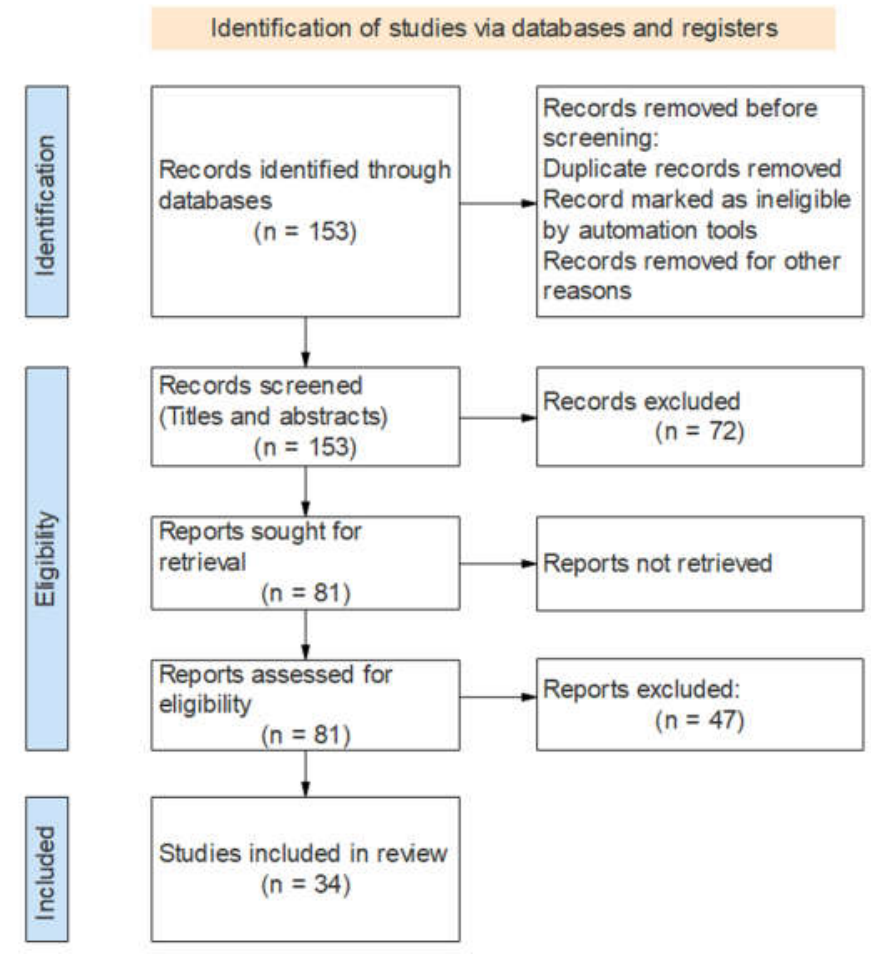

Figure 2. Flow diagram of the systematic review (PRISMA).

\subsection{HTR Paper Publications}

The number of selected articles published between 1999 and 2020 are presented and distributed annually in Figure 3. In general, few articles were published annually, with the years with the highest publication being 2011, 2013, and 2018, followed by the years from 2019 and from 2005 to 2007.

Next, the paper publication channels of journals and conferences are also presented in Table 3. Only 10 papers were published in journals; that is, $29.41 \%$ of all papers were published in journals, with the remaining publications from conferences. Only two conferences have published more than one paper, while the others have published only one paper.

It is important to determine the main authors of the three-phase hybrid rectifiers and thus to know which country leads this technology. For this, Table 4 shows the names of the authors and their affiliations with at least two publications. We can notice that the country leading this three-phase hybrid rectifier system is Brazil. Another important point that reinforces this analysis is that among the 10 articles published in journals, five of them were published by Brazilian actors. 


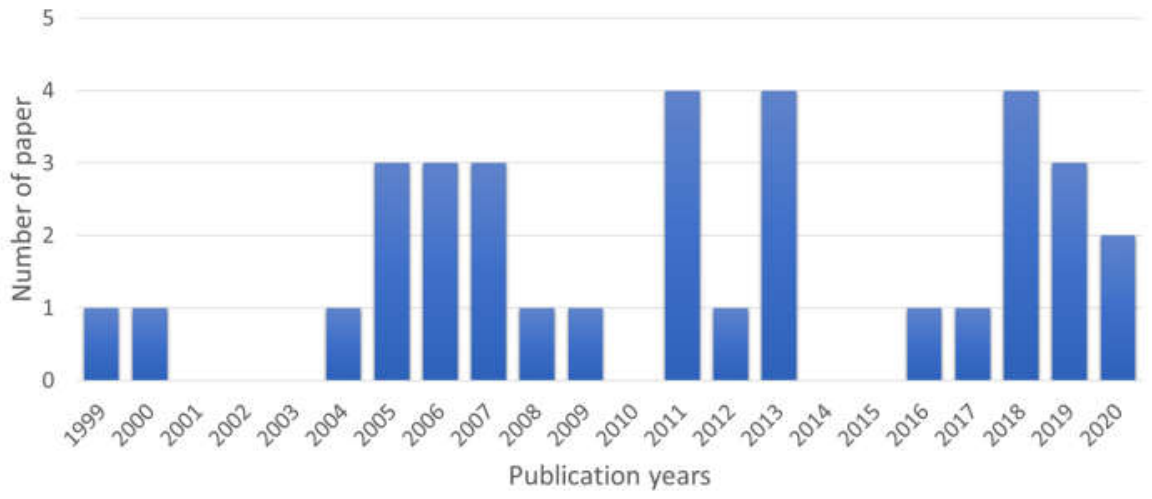

Figure 3. Number of papers published annually.

Table 3. Publication channels.

\begin{tabular}{|c|c|c|c|c|}
\hline Channels & Means & Reference & № & $\%$ \\
\hline IEEE Transactions on Industrial Electronics & Journal & {$[11-13]$} & 3 & 8.82 \\
\hline IEEE Transactions on Power Electronics & Journal & {$[6,14]$} & 2 & 5.9 \\
\hline IEEE Transactions on Industry Applications & Journal & {$[15,16]$} & 2 & 5.9 \\
\hline IET Power Electronics & Journal & {$[17,18]$} & 2 & 5.9 \\
\hline IEEE Transactions on Industrial Informatics & Journal & [19] & 1 & 2.94 \\
\hline $\begin{array}{c}\text { IEEE Power Electronics Specialists } \\
\text { Conference (now is ECCE) }\end{array}$ & Conference & {$[20-23]$} & 4 & 11.76 \\
\hline $\begin{array}{c}\text { IEEE Applied Power Electronics } \\
\text { Conference and Exposition (APEC) }\end{array}$ & Conference & {$[24-26]$} & 3 & 8.82 \\
\hline $\begin{array}{c}\text { 1st Global Power, Energy and Communication } \\
\text { Conference (GPECOM) }\end{array}$ & Conference & {$[2]$} & 1 & 2.94 \\
\hline $\begin{array}{c}\text { Conference Record of the } 1999 \text { IEEE } \\
\text { Industry Applications Conference }\end{array}$ & Conference & {$[10]$} & 1 & 2.94 \\
\hline $\begin{array}{c}\text { IEEE International Symposium on } \\
\text { Industrial Electronics }\end{array}$ & Conference & {$[27]$} & 1 & 2.94 \\
\hline $\begin{array}{c}\text { 7th International Conference on Power } \\
\text { Electronics }\end{array}$ & Conference & {$[28]$} & 1 & 2.94 \\
\hline $\begin{array}{c}\text { IEEE Industry Applications Society } \\
\text { Annual Meeting }\end{array}$ & Conference & {$[29]$} & 1 & 2.94 \\
\hline $\begin{array}{c}\text { Twenty-Seventh Annual IEEE Applied } \\
\text { Power Electronics Conference and } \\
\text { Exposition (APEC) }\end{array}$ & Conference & {$[30]$} & 1 & 2.94 \\
\hline $\begin{array}{c}\text { International Conference on Electrical } \\
\text { Machines and Systems (ICEMS) }\end{array}$ & Conference & {$[31]$} & 1 & 2.94 \\
\hline $\begin{array}{c}\text { 19th European Conference on Power } \\
\text { Electronics and Applications }\end{array}$ & Conference & {$[32]$} & 1 & 2.94 \\
\hline $\begin{array}{l}\text { IEEE International Conference of Safety } \\
\text { Produce Informatization (IICSPI) }\end{array}$ & Conference & {$[33]$} & 1 & 2.94 \\
\hline $\begin{array}{l}\text { IEEE International Power Electronics and } \\
\text { Application Conference and Exposition }\end{array}$ & Conference & {$[34]$} & 1 & 2.94 \\
\hline $\begin{array}{c}\text { IEEE 9th International Power Electronics } \\
\text { and Motion Control Conference }\end{array}$ & Conference & {$[35]$} & 1 & 2.94 \\
\hline $\begin{array}{l}\text { 31st Annual Conference of IEEE Industrial } \\
\text { Electronics Society (IECON) }\end{array}$ & Conference & {$[36]$} & 1 & 2.94 \\
\hline
\end{tabular}




\begin{tabular}{cllll}
\hline $\begin{array}{c}\text { International Conference on Nanoscience, } \\
\text { Engineering and Technology (ICONSET) }\end{array}$ & Conference & {$[37]$} & 1 & 2.94 \\
\hline XI Brazilian Power Electronics Conference & Conference & {$[38]$} & 1 & 2.94 \\
\hline $\begin{array}{c}\text { 20th European Conference on Power } \\
\text { Electronics and Applications, EPE }\end{array}$ & Conference & {$[39]$} & 1 & 2.94 \\
\hline $\begin{array}{c}\text { 37th Annual Conference of the IEEE } \\
\text { Industrial Electronics Society (IECON) }\end{array}$ & Conference & {$[40]$} & 1 & 2.94 \\
\hline The Journal of Engineering & Conference & {$[41]$} & 1 & 2.94 \\
\hline
\end{tabular}

Table 4. Authors on HTR and the number of papers published.

\begin{tabular}{ccc}
\hline Name of Authors & Affliction (University, Country) & № Papers \\
\hline Luiz Carlos Gomes de Freitas et al. & $\begin{array}{c}\text { Federal University of Uberlandia } \\
\text { (UFU); Brazil }\end{array}$ & 6 \\
\hline Damarco Vieira Costa et al. & $\begin{array}{c}\text { Federal University of Uberlandia } \\
\text { (UFU); Brazil }\end{array}$ & 4 \\
\hline Ricardo Luiz Alves et al. & $\begin{array}{c}\text { Federal University of Santa Catarina } \\
\text { (UFSC); Brazil }\end{array}$ & 3 \\
\hline Jurandir de O. Soares et al. & $\begin{array}{c}\text { São Paulo State University (UNESP); } \\
\text { Brazil }\end{array}$ & 2 \\
\hline Wei-Zhang Song et al. & $\begin{array}{c}\text { Xi'an University of Technology; } \\
\text { China }\end{array}$ & 2 \\
\hline
\end{tabular}

\subsection{Principle of Operation of HTR}

To understand the principle of operation of the HTR, it is essential to analyze the operation through the current path and the power flow distributed between the rectifiers, since the current will pass through the two rectifiers. The explanation the principle of operation is based on the figures represented in subsection 3.2.2., so it can be said that the input currents $\left(I_{a}, I_{b}, I_{c}\right)$ are distributed over two paths, for rectifier $1\left(I_{a 1}, I_{b 1}, I_{c 1}\right)$ and for rectifier $2\left(I_{a 2}, I_{b 2}, I_{c 2}\right)$, and then after being rectified and processed by the respective converters, the two output currents ( $I_{o 1}$ and $I_{o 2}$, respectively) in DC are added in the DC bus, thus obtaining the current of output $\left(I_{o}\right)$ of the HTR, since the two rectifiers are connected in parallel $[2,6,13,16-18,20,23,25,26,28,32,34,36,40]$. In a specific way, we will analyze the operation by part, being for the structure of rectifier 1 and then for rectifier 2 . Rectifier 1.

The structure of rectifier 1 can be formed in two modes; the first is formed only by a three-phase bridge with six pulses (GRAETZ bridge), while the second is formed by the three-phase bridge with six pulses (GRAETZ bridge) associated in series by a converter BOOST. In the first mode, the output voltage is not controlled, and it is not possible to impose the current waveform; in this case, the value of the output voltage depends on the value of the input voltage and the load consumption. In this mode, we can also implement a filter inductive at the input of each phase of the rectifier or implement the inductive filter at the output of the rectifier. These current waveforms, such as the rectangular one, are due to the activation of the diodes, which activate in a switching interval of $30^{\circ}$ and $150^{\circ}$ (considering only a semi-cycle), thus conducting the current in this interval $[20,23,25,28,31,36,38]$. In the second mode, the GRAETZ bridge rectifier is connected in series with a BOOST converter to control the output voltage and reduce the ripples of the rectangular current shape. With an appropriate BOOST inductance value and with a suitable control loop (such as PWM) that provides the appropriate command to the power switch, it is possible to obtain practically negligible ripples on the inductor and a control of the average value of the applied output voltage to the load $[2,16,26,27]$. In this case, the control is done by two loops, the voltage loop, and the current loop, as shown in Figure 4. 
The voltage loop aims to keep the output voltage constant under load variations, and therefore, it receives an output voltage signal (through a voltage sensor) and compares it with a reference voltage $\left(V_{r e f}\right)$ of the same value in order to produce an error $\left(e_{v}\right)$ that will be used to change the amplitude of the current signal so that the PWM block can generate the proper pulse widths for controlling the output voltage. In this case, the current loop only has the purpose of imposing the current amplitude (by means of a reference signal of constant value), to allow a certain desired current value (thus allowing a better power distribution in the HTR) and rectangular in shape. Note that some hybrid structures (not all) may have the GRAETZ bridge rectifier 1 and BOOST converter with some minor modifications to allow a correct operation; the modification consists of dividing the BOOST diode and the BOOST inductor, as shown in Figure $4[2,3,6,21,29,34]$.

This structure has very interesting characteristics, being robust, simple, reliable, low volume, low financial cost, and widely applied in low power devices; however, it cannot be used for high power levels, because its input currents have a total harmonic distortion current (THDi) of approximately $30 \%$ and a PF of $95 \%$, which does not meet the IEC 610003-2/61000-3-4 standards [22,27,28]. Given the qualities of this rectifier (robust, simple, reliable, low volume, low financial cost), it is interesting to combine intelligently (hybrid) with another rectifier to take advantage of the qualities of each one.

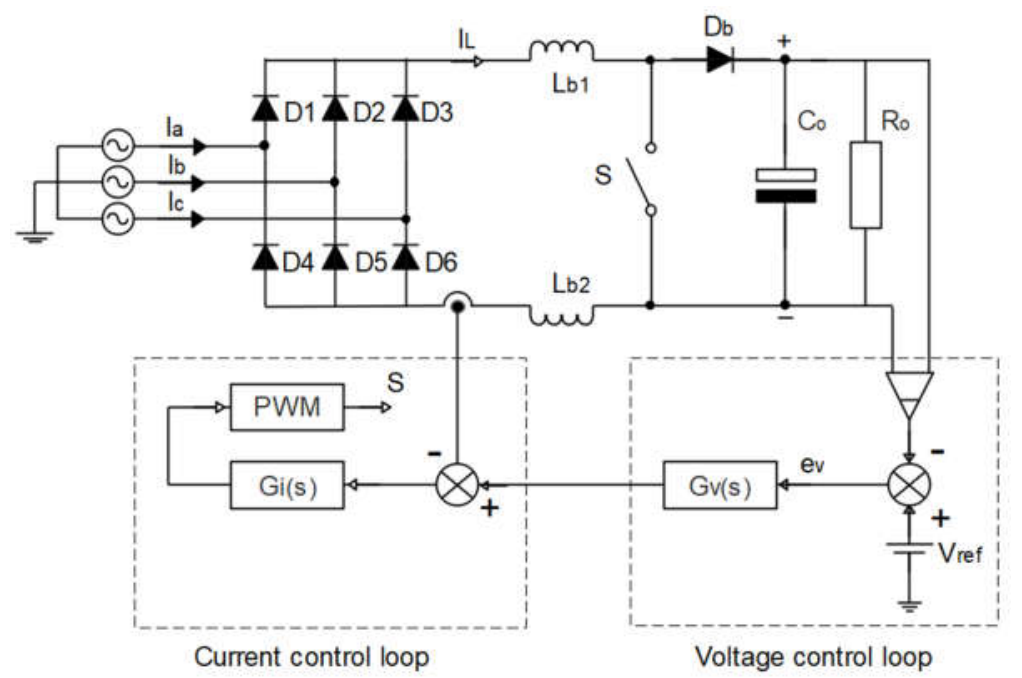

Figure 4. GRAETZ bridge rectifier with BOOST converter and respective control system.

Rectifier 2

Since it is a three-phase hybrid rectifier and knowing how rectifier 1 works, rectifier 2 must function intelligently, thus conducting the electric current (considering the analysis in a semi-cycle) in periods when rectifier 1 does not conduct the current, and rectifier 2 must allow the current to pass to a certain level conditioned to the level driven by rectifier 1. This way, the current is conducted in every semi-cycle in an intelligent way, taking advantage of the benefits of each rectifier. Rectifier 2 must be able to control (impose) the current waveform. It must also be able to control the average value of the output voltage applied to the load, since the value of the output voltage must be the same for the two rectifiers $[2,3,6,21,29,34]$.

Note that theoretically, any three-phase rectifier with PWM control that allows changing the current waveform can be used as rectifier 2 within the structure of an HTR $[2,21]$.

In this way, unidirectional rectifiers and bidirectional rectifiers can be used. In the case of a unidirectional rectifier, the modular three-phase rectifier with BOOST converter and PFC can be used $[2,20,25,36]$; the three-phase modular rectifier with SEPIC converter 
and PFC [16,23,28,29,38]; and the three-phase VIENNA rectifier with PFC [6,18,27], as well as their versions known as the three-phase Delta-switch rectifier with PFC $[13,32,40]$ and the three-phase rectifier Star-switch with PFC [17,41]. In the case of a bidirectional rectifier, the three-phase PWM rectifier of the BOOST type with PFC can be used $[26,31,34]$.

These rectifier structures, by permitting the output voltage regulation and power factor correction, show a low THD and high PF. Thus, they are capable of complying with the norm IEC 61000-3-2/61000-3-4, which is compulsory for many power electronic converters aimed at a high quality of electric energy. Therefore, it is of great interest to combine the rectifiers and obtain advantages of both rectifiers.

Unidirectional three-phase modular rectifier with BOOST converter: It is a structure composed of three single-phase blocks, each block being composed of a single-phase rectifier and a BOOST converter with active power factor correction. The operation of a block is similar with the other blocks, so it is enough to explain just one block. Some studies present these rectifiers with an isolation transformer at the entrance of each phase (or block) to avoid the current interactions between the phases, as illustrated in Figure 5 $[12,14,20,25,36]$. Another study presents this structure without the isolation transformer, but it replaced the BOOST inductor with a coupled inductor to mitigate current interactions, as shown in Figure 6 [2]. The control with PFC is given by two loops, the voltage loop, and the current loop (three current loops, one for each phase), as can be seen in Figure 5 and Figure 6. The voltage loop controls the output voltage by means of a signal of the output voltage that will be compared with a reference voltage $\left(V_{\text {ref }}\right)$, thus generating a tenon error $\left(e_{v}\right)$ being sent to the voltage compensator $\left(G_{V(S)}\right)$. Then, the obtained signal is distributed over the current of each phase, this being multiplied by the signal of the reference voltage of the sinusoid $\left(V_{\text {ref.a }}, V_{\text {ref.b }}, V_{\text {ref.c }}\right)$ (synchronized with the mains voltage). Then, an adder receives this signal and the current signal from the inductor (obtained by means of a current sensor), and the generated signal is applied to their respective current compensators $\left(G_{i(S)}\right)$ and to the PWM modulator that will generate the gate signals for the corresponding power switch (S) $[2,12,20]$.

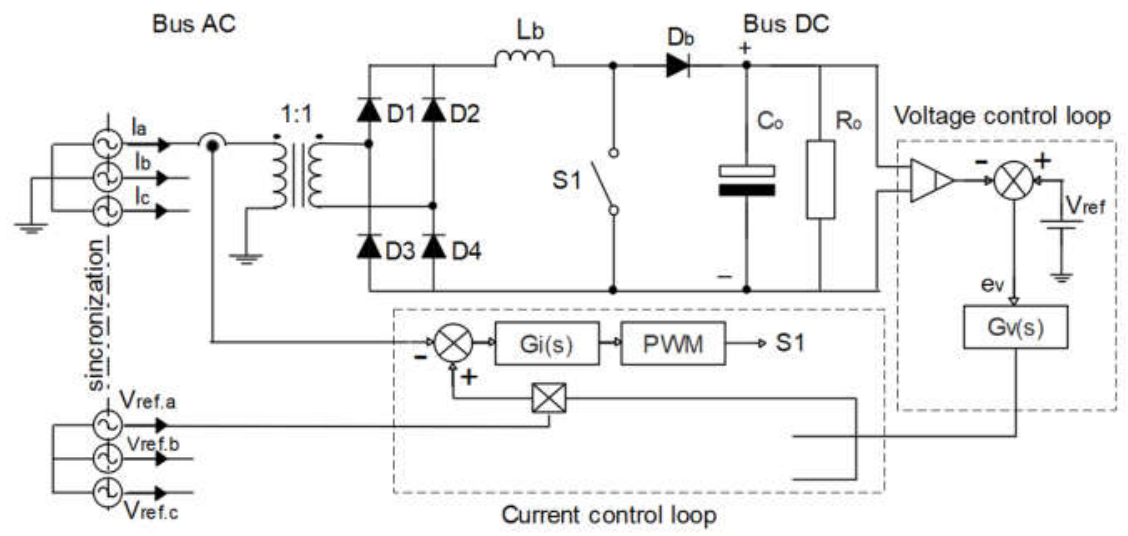

Figure 5. Modular three-phase rectifier with BOOST converter and isolation transformer. 


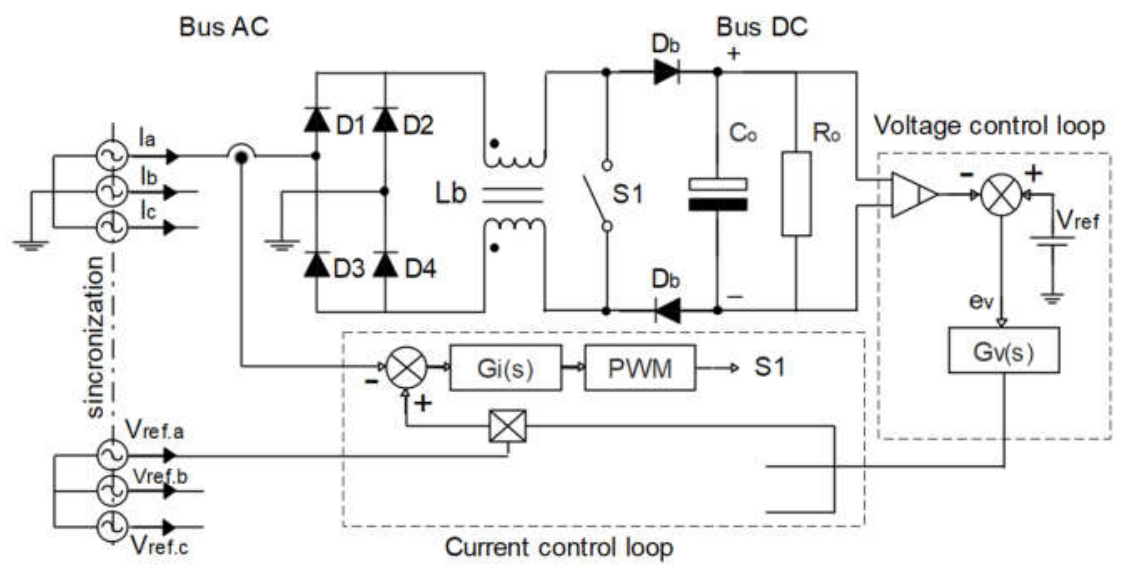

Figure 6. Modular three-phase rectifier with BOOST converter and coupled inductor.

Unidirectional three-phase modular rectifier with SEPIC converter: It is also a structure composed of three single-phase blocks, each block being composed of a singlephase rectifier and a SEPIC converter with active power factor correction. This structure is interesting because it allows the connection of three modules to work as a three-phase rectifier without any current interaction between the phases, thanks to the series capacitor that guarantees, under any operating conditions, the decrease of the current that flows through the input inductor (thus, the imposition of the input current does not depend strongly on the level of the output voltage) $[12,17,20,22]$. There are two forms of constitution of this rectifier, which are based on the exposure of the SEPIC inductor. The first form is based on the conventional SEPIC converter but with a small modification of dividing the SEPIC inductor and capacitor by two (one on the positive and one on the negative) [12,22], as shown in Figure 7. The second way is to implement the SEPIC inductor at the input of each rectifier phase $[16,19,29,30,38]$. Control is also provided by two loops: the voltage loop and the current loop. The process of the voltage loop and the reference signal that goes to the current compensator $\left(G_{i(S)}\right)$ is basically the same as that already described in the modular rectifier with a BOOST converter. However, in this system, each current compensator $\left(G_{i(S)}\right)$ with the PWM modulator generates a suitable signal for the power switch of the SEPIC converter.

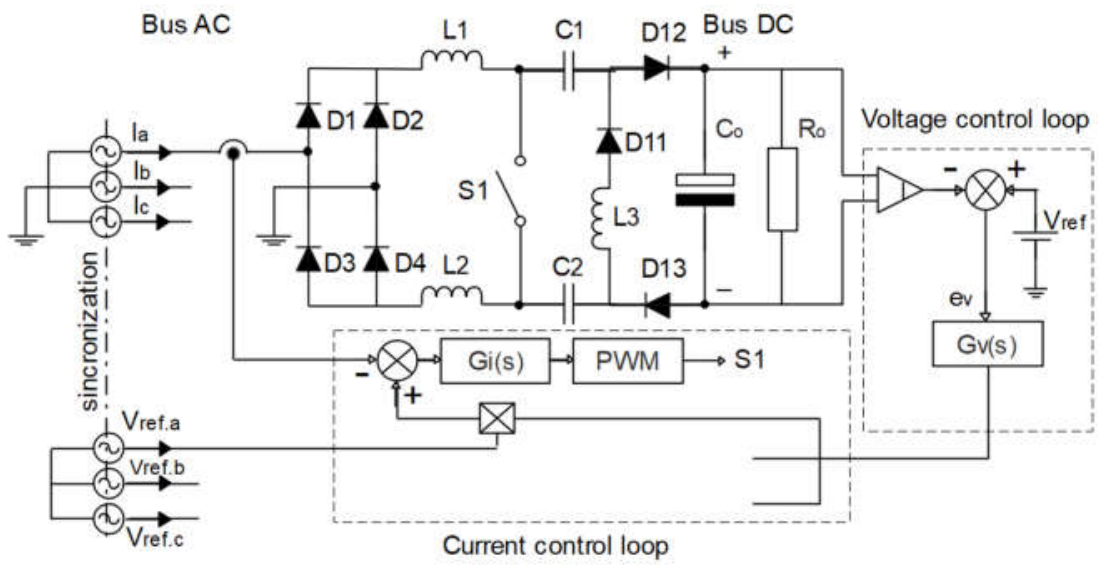

Figure 7. Modular three-phase rectifier with SEPIC converter.

Unidirectional VIENNA rectifier: The two-level VIENNA rectifier is widely used, as shown in Figure 8. This structure works with the three phases without the need for neutral, and the inductor is implemented at the input of each phase of the rectifier, with 
each phase being controlled by a toggle switch. Control is also provided by two loops: the voltage loop and the current loop (one current loop for each phase). The process of the voltage loop and the reference signal that goes to the current compensator $\left(G_{i(S)}\right)$ for each phase is basically the same as that already described in the modular rectifier with the BOOST converter, as can be seen in Figure 8. However, in this system, each compensator of current $\left(G_{i(S)}\right)$ with the PWM modulator generates a gate signal suitable for the power switch (S) of the respective rectifier. It is important to note that when applying this classic control to this topology, there is a need to synchronize the carriers ("sawtooth" waves) of the PWM modulator in each phase. In this way, the control causes the cyclic ratio for the phase with the highest current (and the highest current reference) to present the highest cyclic ratio, respecting this condition for the controllability of the currents $[6,18,27]$. However, other versions of this two-level VIENNA rectifier, such as the Delta-switch rectifier and the Star-switch rectifier, were also studied and analyzed in more detail in Section 3.2.1.

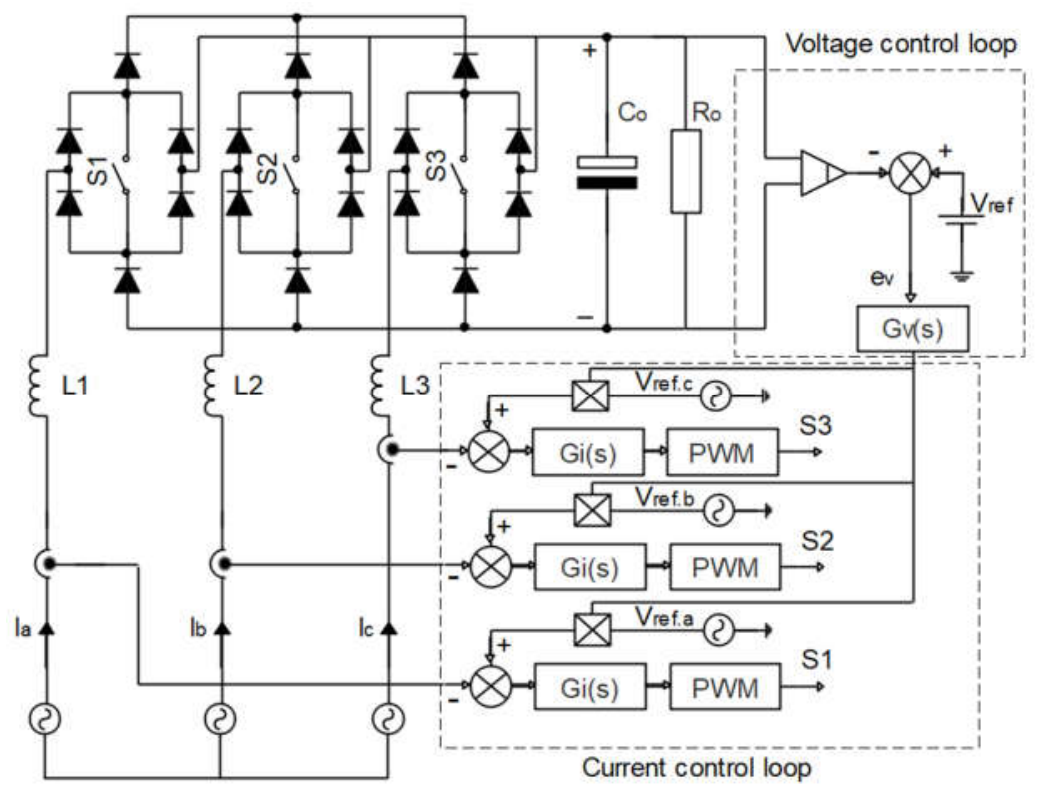

Figure 8. VIENNA rectifier with PFC and respective control system.

BOOST-type PWM bidirectional three-phase rectifier: It is widely used when good sinusoidal currents are desired. This structure also has an inductor in each phase and is controlled by six power switches, as shown in Figure 9. Control is also given by two loops: the voltage loop and the current loop. The voltage loop and reference signal process that goes to the current compensator $\left(G_{i(S)}\right)$ is basically the same as that described in the VIENNA rectifier. In this case, each current compensator $\left(G_{i(S)}\right)$ with the PWM modulator generates two port signals suitable for the rectifier system [26,34]. 


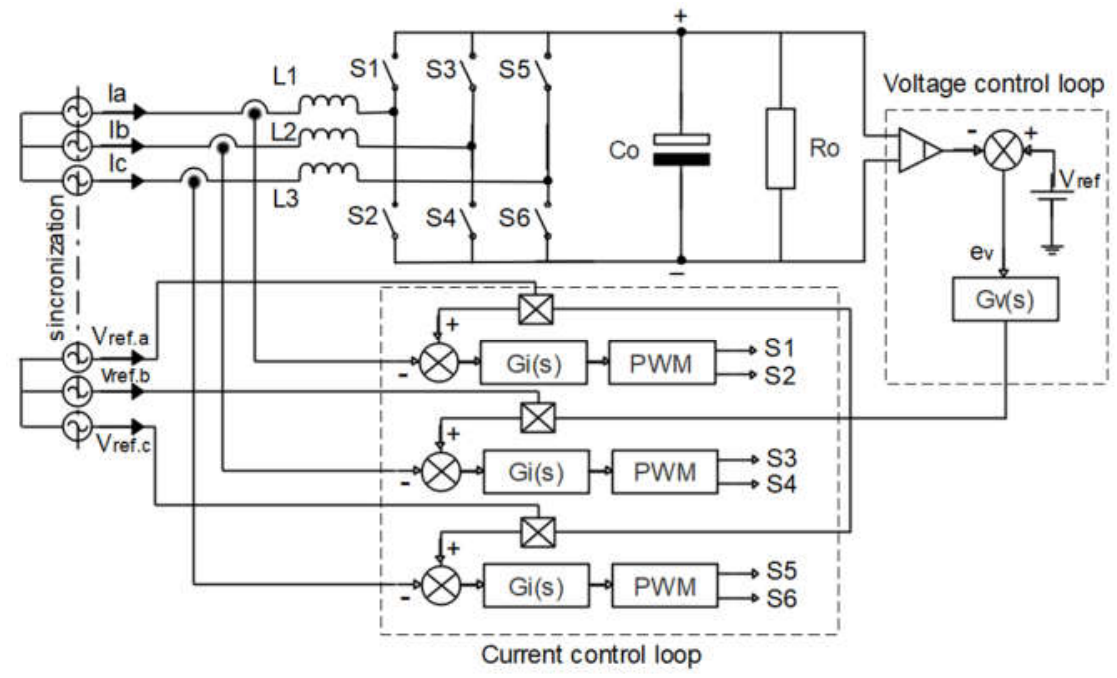

Figure 9. BOOST-type PWM rectifier with PFC and respective control system.

\section{Power Distribution}

The distribution of power between the rectifiers is an important factor, as it determines the proper functioning of the three-phase hybrid rectifier and determines the quality of the input current that is to be obtained. Since the value of the output voltage is the same for the rectifiers, then the current distribution will determine the power distribution. At first, it is known that the input current is divided into two paths (two rectifiers connected in parallel), so it is only necessary to determine the right amount of current for each rectifier, thus determining the right power distribution between the rectifiers [2]. Power distribution is possible in two ways, depending on the structure of the HTR. In the first mode, the UHTR structure shown in Figure 10 is used, and the second mode is used in the configuration shown in Figure 11 [2,6,18,25,27].

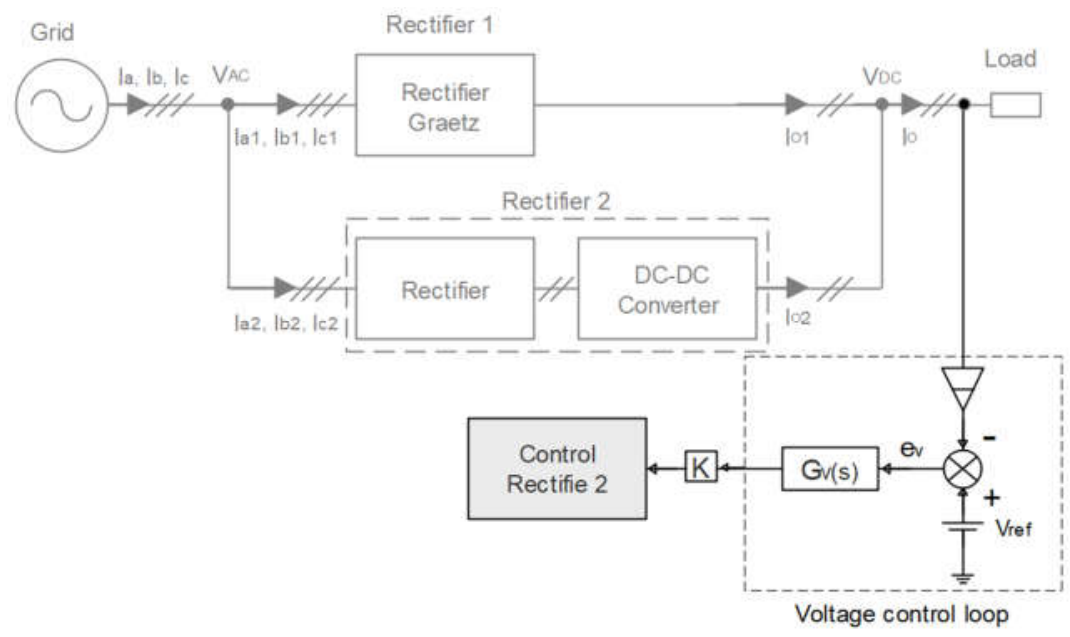

Figure 10. Representation of the first mode for power distribution in the HTR using the K gain. 


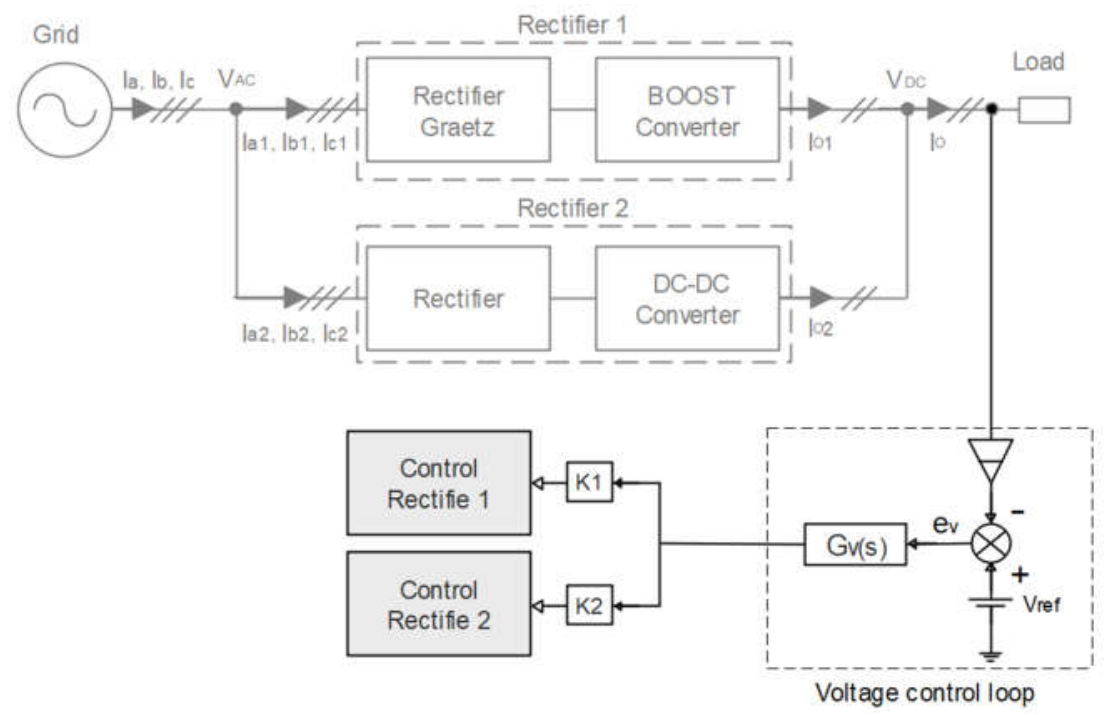

Figure 11. Representation of the second mode for power distribution in the HTR using the K1 and K2 gains.

In the first mode, there is no direct control of the current in rectifier 1, but if you have the current control in rectifier 2, this will soon be the dominant one; that is, it is through the control of rectifier 2 that the current distribution is determined. This is possible, for example, by changing the gain $(\mathrm{K})$ of the output voltage signal that goes to the current loop of the control of the respective rectifier, as shown in Figure 10. In the second mode, it is possible to control the current in the two rectifiers. Thus, the power distribution is made by controlling the currents of the two rectifiers. This is possible by changing the gains $\left(K_{1}\right.$ and $\left.K_{2}\right)$ of the output voltage signal that goes to the control current loops of respective 1 and rectifier 2 respectively, as shown in Figure $11[6,18,21,25,27]$.

Considering that the objective of the UHTR is to impose a sinusoidal current, it will be possible to find a gain relationship between $K_{1}$ and $K_{2}$. In this case, the ratio value will determine the power distribution [21]. The list is given by the following Formula (1).

$$
0 \leq \frac{K_{2}}{K_{1}} \leq 0.5
$$

For a correct operation of the HTR, it is important that this ratio is set close to 0.5 and the ratio should not be higher than that value [21] to obtain a balanced distribution, as shown in Figure 12.

If the ratio value would be greater than 0.5 , the input currents in the HTR will be distorted, as shown in Figure 13. This should be avoided as the objective is for the HTR to have a low THDi value [21].

If the value of the ratio is in the range of 0 to 0.5 (example, 0.2 ), rectifier 2 will process most of the nominal power, as shown in Figure 14. This should be avoided too, because the objective is that rectifier 1 processes the largest portion of possible power [21,27].

If the ratio value is close to 0 , rectifier 2 will process all nominal power, and thus, rectifier 1 is out of service [21,25].

This power distribution analysis is used in UHTR but is also valid to a certain extent for the BHTR. The difference is in the established limits of the value of the relationship.

In BHTR, it is understood that theoretically, any combination of power can be performed by each rectifier, and in all cases, the input currents will have a sinusoidal shape. It must also be considered that the objective of the HTR is that rectifier 1 processes the largest portion of the output power. So, the BHTR can work with a ratio greater than or equal to 0.5, as expressed in Formula (2). If the BHTR works with a ratio above 0.5 and close to 1 , rectifier 1 will supply the rated output power, and rectifier 2 processes only the 
energy necessary to reach a sinusoidal current with high PF and low THD, as shown in Figure 15 [26]. This is also an interesting operating mode for the correct functioning of the BHTR.

$$
0.5 \leq \frac{K_{2}}{k_{1}} \leq 1
$$

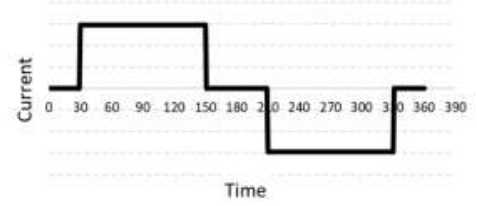

(a)

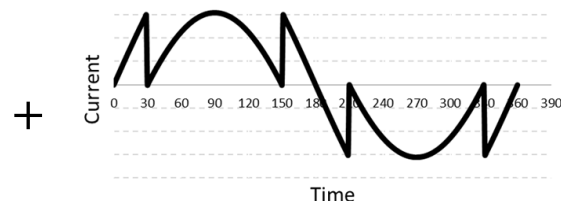

(b)

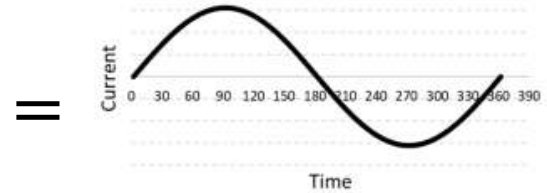

(c)

Figure 12. Current waveforms in phase $a$ of the HTR. (a) Input current in rectifier 1. (b) Input current in rectifier 2. (c) Input current (sinusoidal) in the HTR.

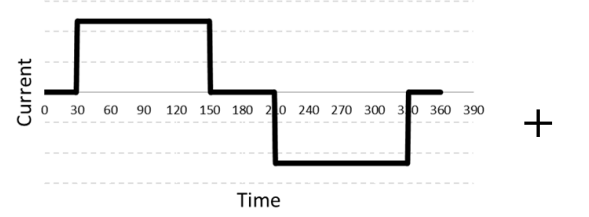

(a)

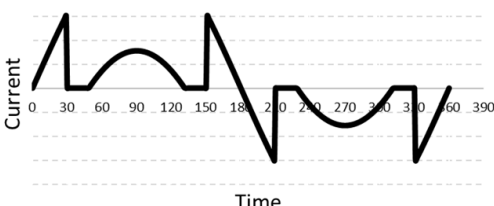

(b)

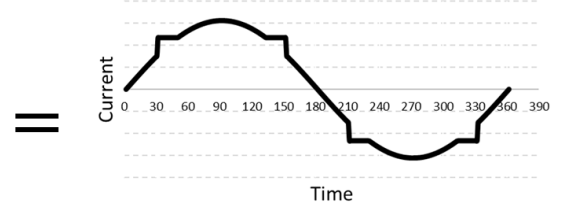

(c)

Figure 13. Current waveforms in phase $a$ of the HTR. (a) Input current in rectifier 1. (b) Input current in rectifier 2. (c) Input current (distorted sinusoidal) in the HTR.

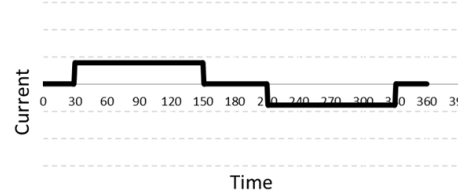

(a)

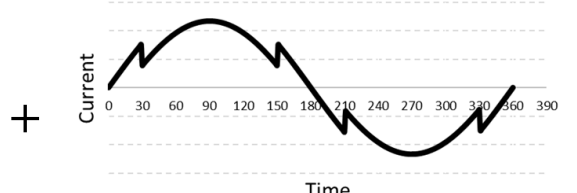

(b)

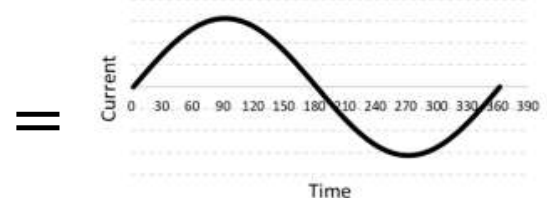

(c)

Figure 14. Current waveforms in phase $a$ of the HTR. (a) Input current in rectifier 1. (b) Input current in rectifier 2. (c) Input current (sinusoidal) in the HTR.

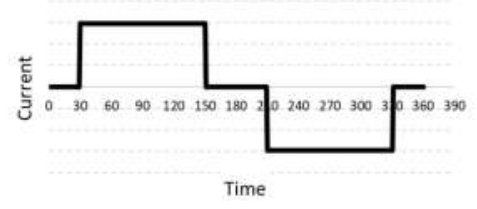

(a)

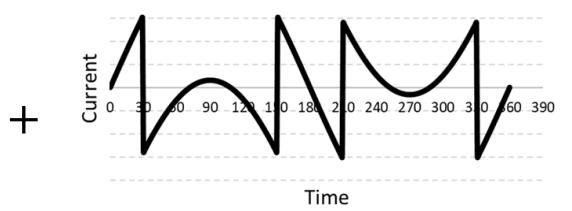

(b)

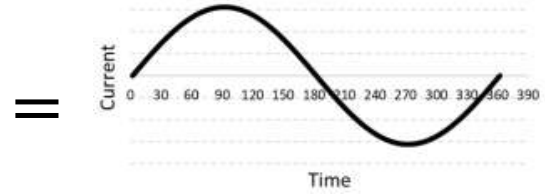

(c)

Figure 15. Current waveforms in phase a of the HTR. (a) Input current at rectifier 1. (b) Input current at rectifier 2. (c) Input current (sinusoidal) at BHTR.

\subsubsection{Classification of HTR}

As mentioned in the operation of the HTR, the type of HTR depends on the type of converter applied to rectifier 2 . Thus, we can have a three-phase hybrid rectifier using a rectifier 2 BOOST, SEPIC, VIENNA, Delta-switch, Star-switch, and PWM BOOST.

Due to the organization of the rectifiers, it is important to investigate and analyze the names given to the different types of existing three-phase hybrid rectifiers. Therefore, in Table 5, the names that were assigned in the HTR found in the literature (paper) are 
shown. We can see that in many papers, they practically do not assign a specific name to the studied HTR, they only describe it as HTR, while other publications (papers) assign a specific name to the studied rectifier. On the other hand, if we analyze, we will see that the names are assigned individually (by paper), and therefore, when we compare these names, we will notice that they do not follow a pattern, which makes the studies of HTR less organized. To improve the organization of the HTR, we propose in Table 5 the appropriate name for each rectifier, as mentioned in the papers. The proposed names are given following a logical form of the constitution of the rectifier so that they can follow a pattern.

Table 5. HTR classification proposed.

\begin{tabular}{|c|c|c|c|}
\hline HTR Name in the Paper & Reference & HTR Name Proposal & Acronym \\
\hline $\begin{array}{c}\text { Hybrid three-phase rectifier with } \\
\text { BOOST converter without isolation } \\
\text { transformer }\end{array}$ & {$[2]$} & $\begin{array}{l}\text { Unidirectional hybrid three-phase } \\
\text { rectifier with BOOST converter on } \\
\text { rectifier } 1 \text { and BOOST converter on } \\
\text { rectifier } 2\end{array}$ & $\begin{array}{l}\text { UHTR- } \\
\text { BR1//BR2 }\end{array}$ \\
\hline $\begin{array}{c}\text { PFC Based Hybrid Multipulse Power } \\
\text { Rectifier (PFC-HMPR) }\end{array}$ & {$[20,25,36]$} & $\begin{array}{l}\text { Unidirectional three-phase hybrid } \\
\text { rectifier with rectifier } 1 \text { and BOOST } \\
\text { converter on rectifier } 2 \text { with } \\
\text { transformer }\end{array}$ & UHTR-R1//BR2 \\
\hline - & {$[16,29]$} & $\begin{array}{l}\text { Unidirectional hybrid three-phase } \\
\text { rectifier with BOOST converters on } \\
\text { rectifier } 1 \text { and SEPIC converter on } \\
\text { rectifier } 2\end{array}$ & $\begin{array}{l}\text { UHTR- } \\
\text { BR1//SR2 }\end{array}$ \\
\hline $\begin{array}{l}\text { Power factor correction non-isolated } \\
\text { hybrid power rectifier (PFC-HPR) }\end{array}$ & $\begin{array}{c}{[12,14,19,22-} \\
24,28,30,38,39]\end{array}$ & $\begin{array}{l}\text { Unidirectional hybrid three-phase } \\
\text { rectifier with rectifier } 1 \text { and SEPIC } \\
\text { converter on rectifier } 2\end{array}$ & UHTR-R1//SR2 \\
\hline $\begin{array}{l}\text { Unidirectional hybrid three-phase } \\
\text { voltage source rectifier (UHTPVSR) }\end{array}$ & {$[6,13,18,21,27,33]$} & $\begin{array}{l}\text { Unidirectional hybrid three-phase } \\
\text { rectifier with BOOST converters on } \\
\text { rectifier } 1 \text { and VIENNA converter on } \\
\text { rectifier } 2\end{array}$ & $\begin{array}{c}\text { UHTR- } \\
\text { BR1//VR2 }\end{array}$ \\
\hline $\begin{array}{l}\text { Hybrid three-phase rectifiers with } \\
\text { single-switch three phase BOOST } \\
\text { rectifier and the DELTA-switch rectifier }\end{array}$ & {$[13,32,40]$} & $\begin{array}{l}\text { Unidirectional hybrid three-phase } \\
\text { rectifier with BOOST converters on } \\
\text { rectifier } 1 \text { and delta-switch converter } \\
\text { on rectifier } 2\end{array}$ & $\begin{array}{c}\text { UHTR- } \\
\text { BR1//DR2 }\end{array}$ \\
\hline- & {$[13,17,41]$} & $\begin{array}{l}\text { Unidirectional hybrid three-phase } \\
\text { rectifier with BOOST converter on } \\
\text { rectifier } 1 \text { and Star-switch converter on } \\
\text { rectifier } 2\end{array}$ & $\begin{array}{c}\text { UHTR- } \\
\text { BR1//StR2 }\end{array}$ \\
\hline $\begin{array}{l}\text { Unidirectional hybrid three-phase } \\
\text { voltage source rectifier (UHTPVSR) }\end{array}$ & {$[26,34]$} & $\begin{array}{c}\text { Bidirectional hybrid three-phase } \\
\text { rectifier with BOOST converter on } \\
\text { rectifier } 1 \text { and PWM BOOST converter } \\
\text { on rectifier } 2\end{array}$ & $\begin{array}{l}\text { BHTR- } \\
\text { BR1//BR2 }\end{array}$ \\
\hline - & {$[26,31]$} & $\begin{array}{c}\text { Bidirectional hybrid three-phase } \\
\text { rectifier with rectifier } 1 \text { and PWM } \\
\text { BOOST converter on rectifier } 2 \text { with } \\
\text { transformer }\end{array}$ & BHTR-R1//BR2 \\
\hline
\end{tabular}

\subsubsection{HTR Design}

The HTR using the BOOST converter on rectifier 2 are referred to as UHTR-BR1//BR2 and UHTR-R1//BR2, as proposed in Table 5. 
UHTR-BR1//BR2 is represented in Figure 16 and was proposed in 2019 [2]. It consists of rectifier 1 (GRAETZ bridge rectifier associated with a BOOST converter) associated in parallel to rectifier 2 (modular three-phase rectifier with BOOST converter). The BOOST converters have undergone a change to avoid interactions between the three modular rectifiers that make up rectifier 2 . The change is made by exchanging the BOOST converter inductor for a coupled inductor, and a diode is implemented in the inverse of the current interaction, thus forcing the current to travel in the normal direction [2].

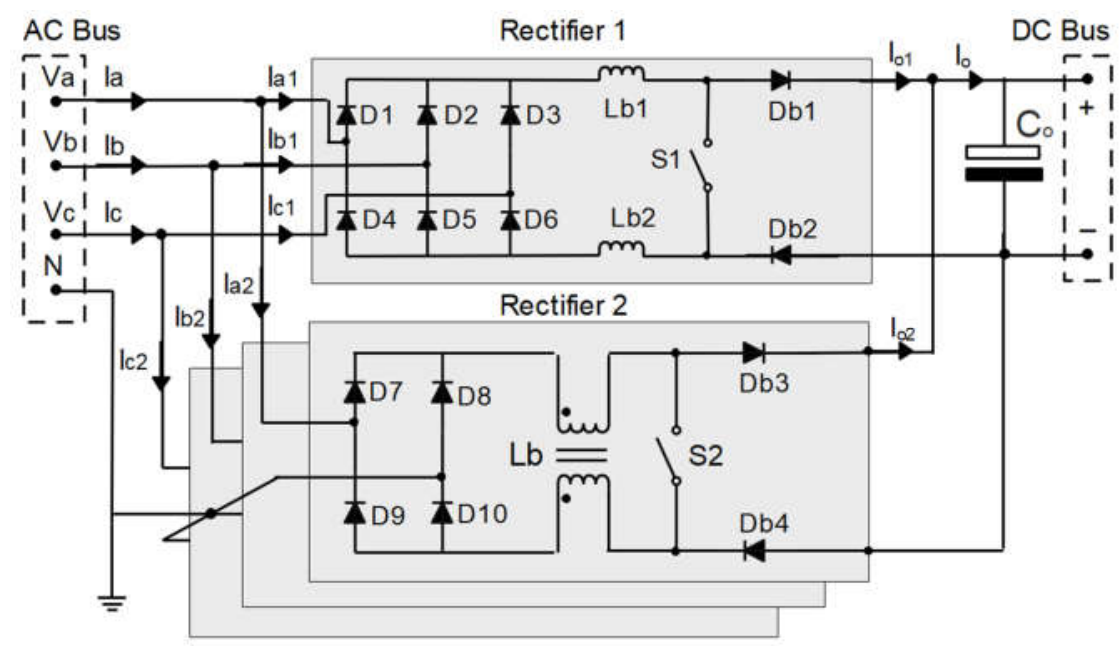

Figure 16. Configuration of the electrical circuit of the UHTR-BR1//BR2.

The UHTR-R1//BR2 is shown in Figure 17 and proposed for the first time in 2005. It consists of rectifier 1 (GRAETZ bridge rectifier with inductive filter) associated in parallel to rectifier 2 (modular three-phase rectifier with BOOST converter). Each rectifier module 2 has an isolation transformer to avoid current interactions between the rectifiers. This rectifier can impose 12-multilevel input currents [20,36], as shown in Figure 18 and sinusoidal currents [25].

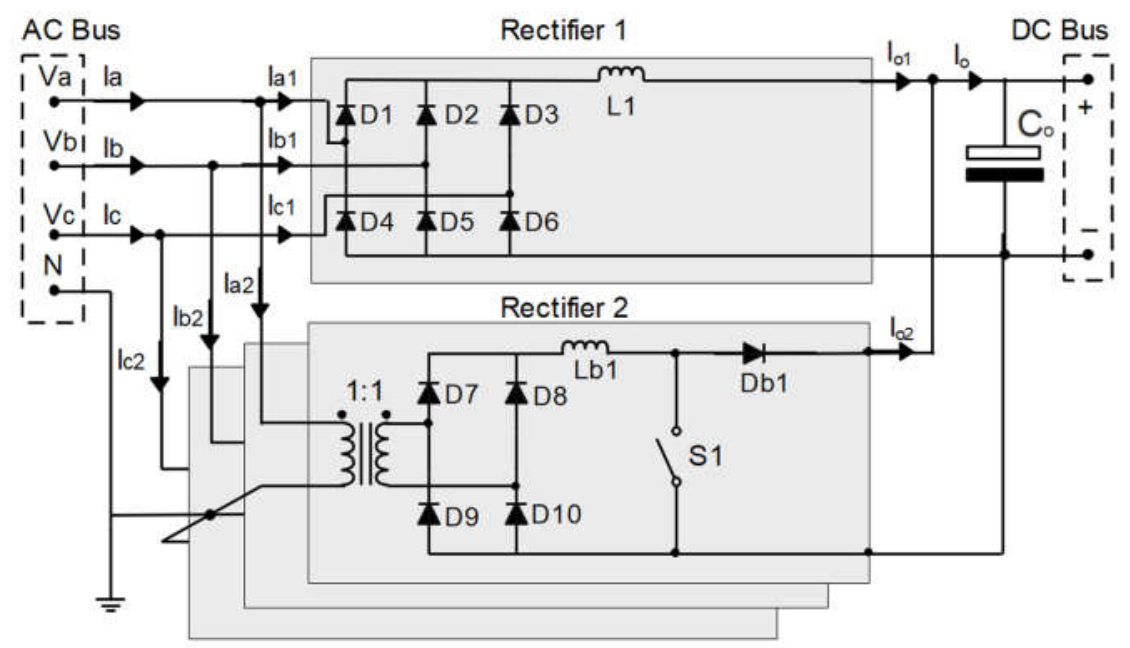

Figure 17. Configuration of the electrical circuit of the UHTR-R1//BR2. 


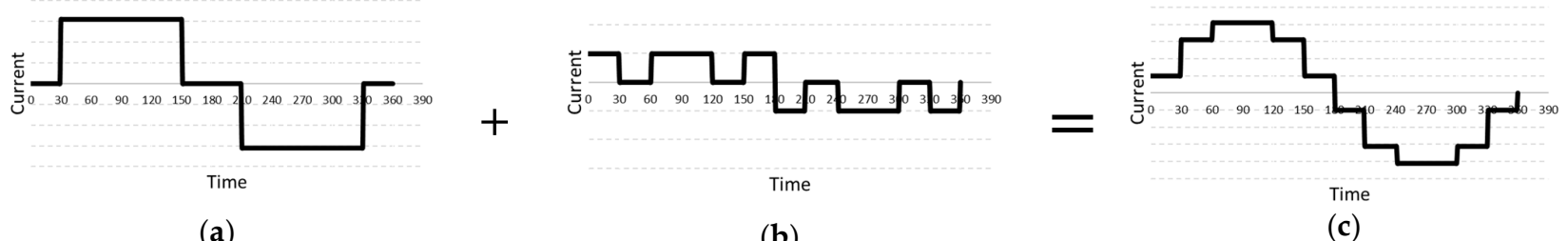

(a)

(b)

(c)

Figure 18. Current waveforms in phase a of the HTR. (a) Input current at rectifier 1. (b) Input current at rectifier 2. (c) Input current (12 multilevels) at HTR.

HTR using the SEPIC converter on rectifier 2 were first proposed in 2004 [22]; these are classified and named as UHTR-BR1//SR2 and UHTR-R1//SR2 as proposed in Table 5, and this classification is due to the implementation of a BOOST converter in rectifier 1 . In the first case, UHTR-BR1//SR2 can control the output voltage due to the BOOST converter, whereas in UHTR-R1//SR2, the output voltage control is not only current imposition.

UHTR-BR1//SR2 is shown in Figure 19 consisting of rectifier 1 (GRAETZ bridge rectifier with BOOST converter and inductive filter on the AC bus) associated in parallel to rectifier 2 (modular three-phase rectifier with SEPIC converter). This rectifier can impose sinusoidal input currents, as shown in Figure 20 [16,29].

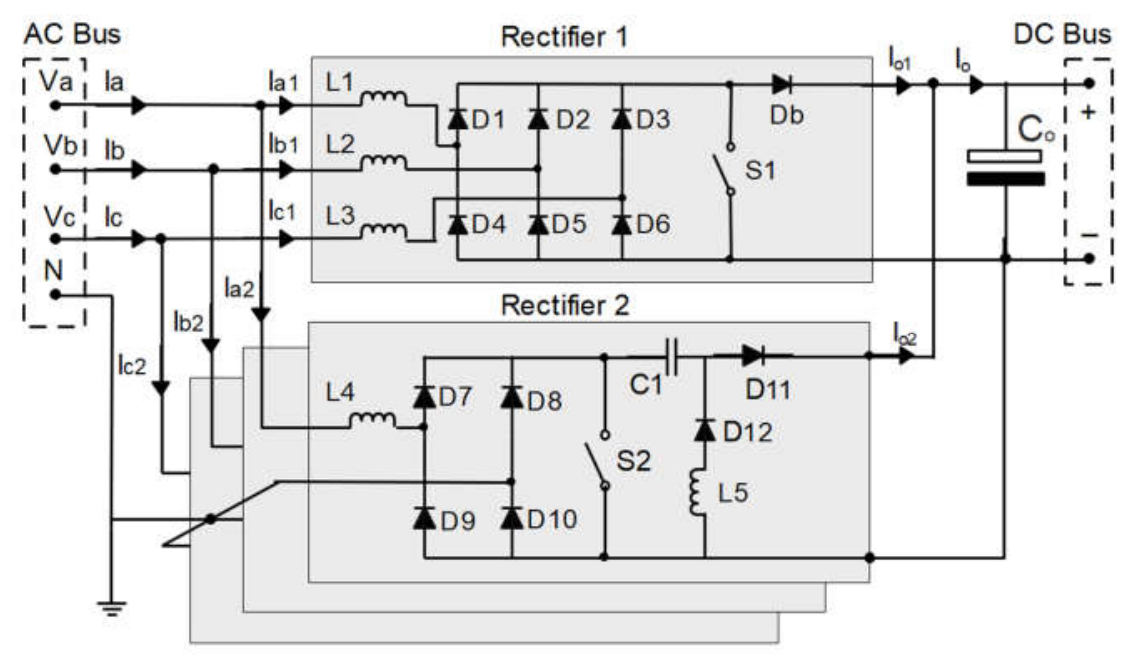

Figure 19. Configuration of the electrical circuit of UHTR-BR1//SR2.

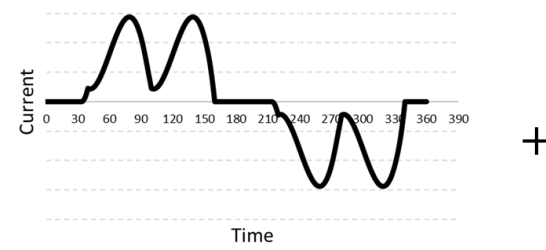

(a)

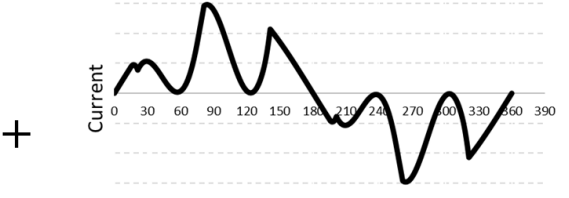

Time

(b)

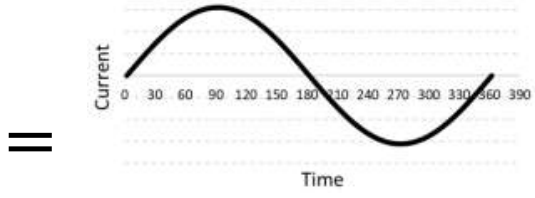

(c)

Figure 20. Current waveforms in phase $a$ of the HTR. (a) Input current in rectifier 1. (b) Input current in rectifier 2. (c) Input current (sinusoidal) in the HTR.

The UHTR-R1//SR2 is shown in Figure 21 consisting of rectifier 1 (GRAETZ bridge rectifier with inductive filter) associated in parallel to rectifier 2 (modular three-phase rectifier with SEPIC converter). This rectifier can impose sinusoidal input currents, as shown in Figure 12 [23,28] and Figure 20 [19,30,38]; it can also impose 12 multilevel input currents [12,14,22], according to Figure 18. 


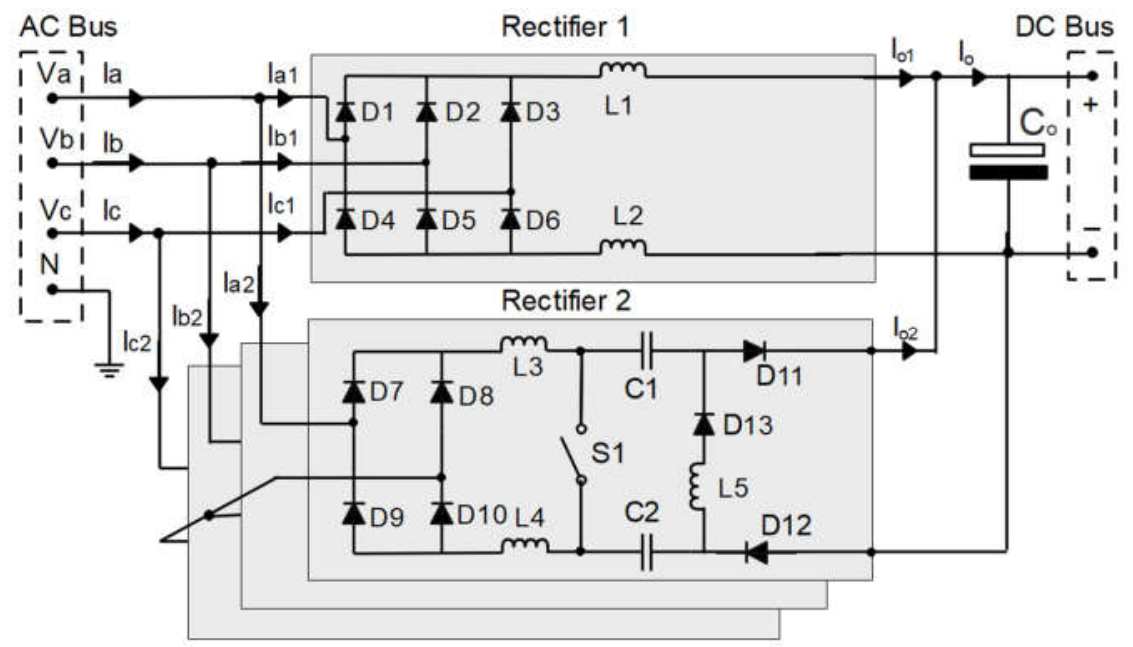

Figure 21. Configuration of the electrical circuit of UHTR-R1//SR2.

HTR using the two-level VIENNA rectifier on rectifier 2 were proposed in $[21,27]$ and developed in $[6,18]$. The rectifier proposed in Table 5 as UHTR-BR1//VR2 is also made up of two rectifiers, as shown in Figure 22: rectifier 1 (three-phase GRAETZ bridge rectifier associated with a BOOST converter, to control the output voltage) in parallel with the twolevel VIENNA rectifier. It can control the output voltage to keep it constant and impose sinusoidal input currents, combining the different forms of current imposed on rectifier 1 and rectifier 2, as shown in Figure 12.

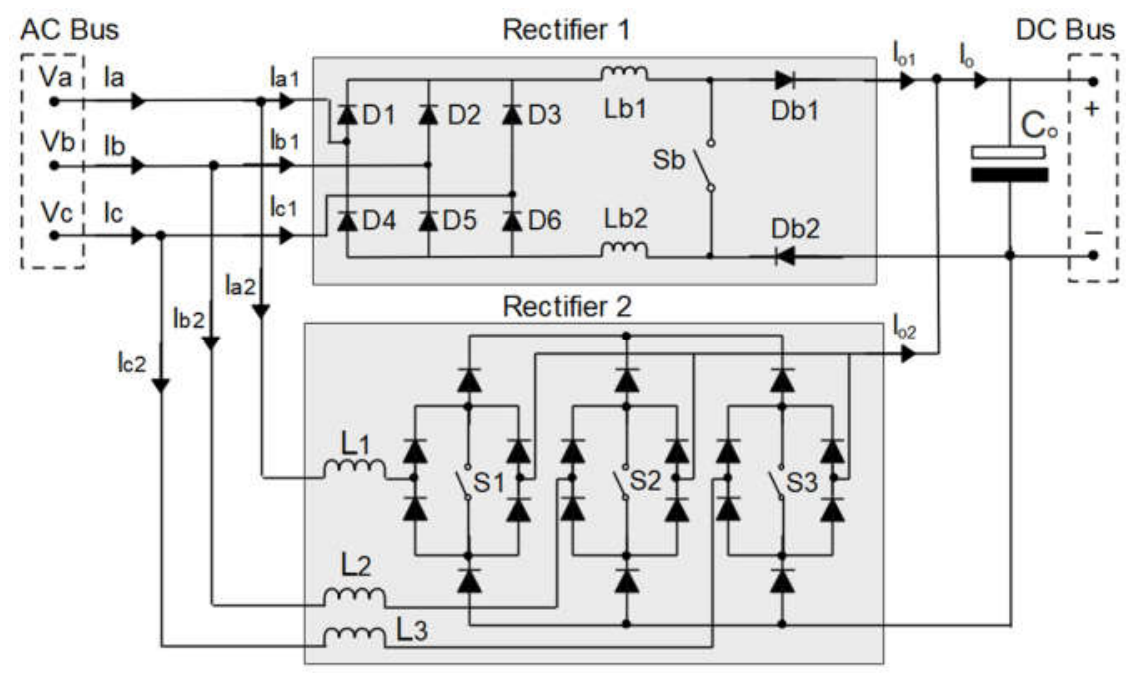

Figure 22. Configuration of the electrical circuit of UHTR-BR1//VR2.

There are other varieties of VIENNA three-phase rectifiers, but the structure of the two-level VIENNA rectifier is the most used to compose an HTR. However, other VIENNA rectifier structures are found in the literature, and they are also used as HTR rectifier 2. These structures are known as the Delta-switch three-phase rectifier and the Star-switch three-phase rectifier.

The Delta-switch rectifier has this name because it has six power switches connected in a delta configuration, together with a three-phase six-diode rectifier. This Delta-switch rectifier is connected in parallel with a GRAETZ bridge rectifier with a BOOST converter proposed in $[13,32,40]$ and proposed in Table 5 as UHTR-BR1//DR2, as represented in Figure 23. The Star-switch rectifier consists of a three-phase bridge with six diodes and 
three power switches connecting the input phases to the neutral point of the DC bus. This Star-switch rectifier was also connected in parallel with a GRAETZ bridge rectifier with BOOST converter, as proposed in $[14,17,41]$ and proposed in Table 5 as UHTR-BR1//StR2, as represented in Figure 24.

Both the UHTR-BR1//DR2 and the UHTR-BR1//StR2 can control the output voltage and impose sinusoidal input currents; this sinusoid is the combination of the rectifier 1 input current waveforms and rectifier 2, as shown in Figure 12.

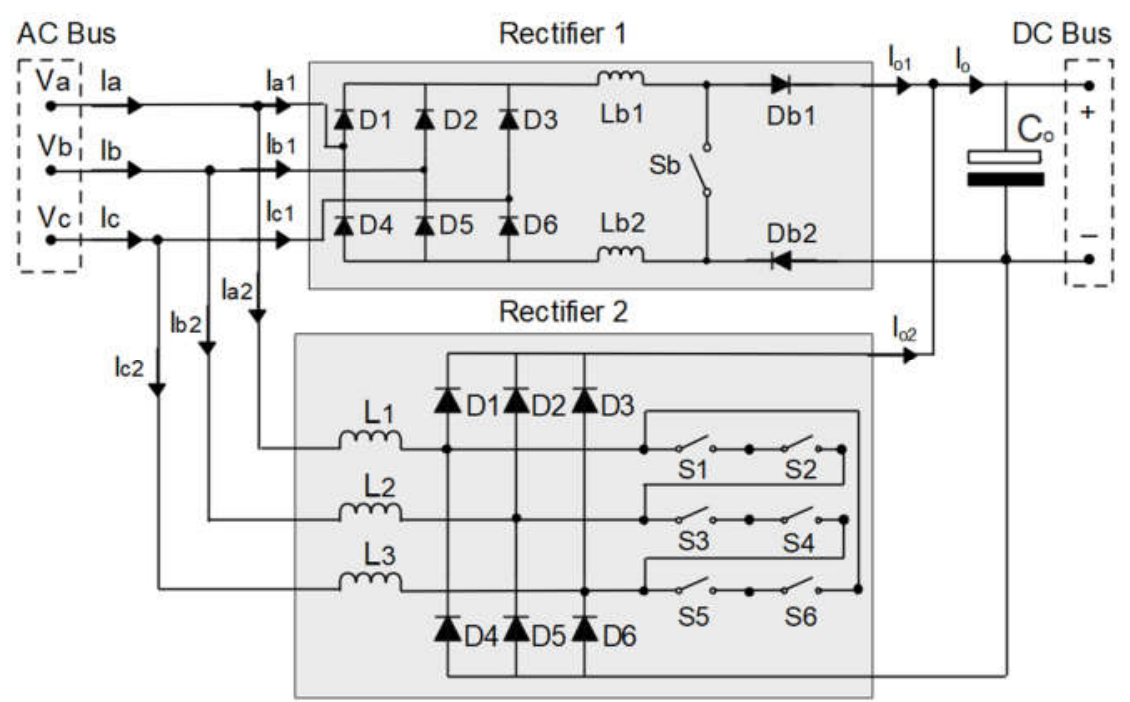

Figure 23. Configuration of the electrical circuit of UHTR-BR1//DR2.

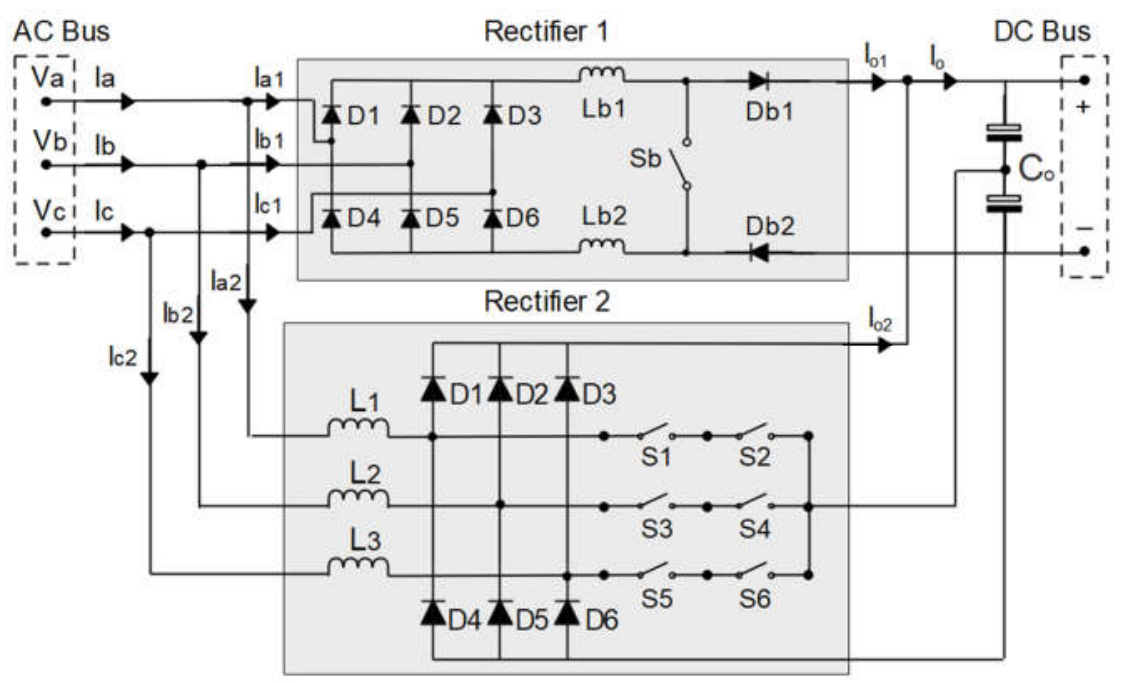

Figure 24. Configuration of the electrical circuit of the UHTR-BR1//StR2.

In the case of BHTR, only one possible structure was found in the literature [26], which is composed of two rectifiers, as shown in Figure 25. Rectifier 1 (three-phase GRAETZ bridge rectifier associated with a single switch BOOST converter) in parallel with the PWM BOOST-type rectifier composed of six power switches. This rectifier maintains the output voltage in a controlled manner and can impose sinusoidal input currents. The imposed sinusoidal current comes from the combination of the different forms of current imposed on rectifier 1 and rectifier 2, as shown in Figure 12 and Figure 15; it is proposed in Table 5 as BHTR-BR1//BR2. 


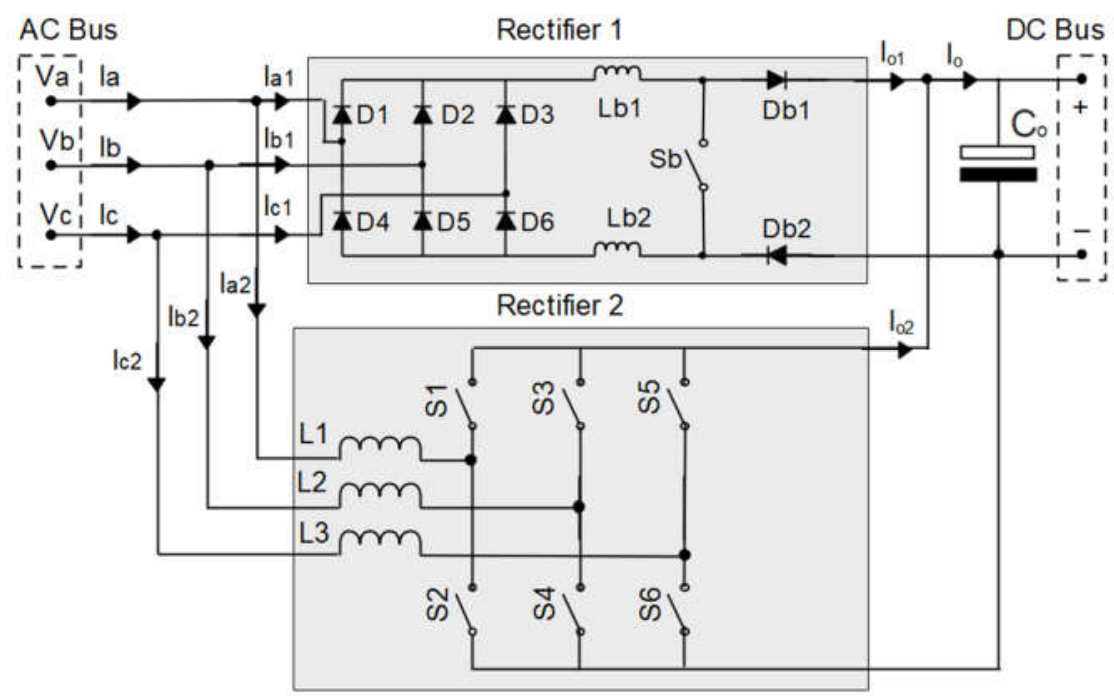

Figure 25. Configuration of the electrical circuit of BHTR-BR1//BR2.

Another structure named in Table 5 as BHTR-R1//BR2 and represented in Figure 26 comes from BHTR-BR1//BR2; its design was proposed in [26] and later developed in [31]. It differs from BHTR-BR1//BR2, because it does not have the ability to control the output voltage, so the level of the output voltage is conditioned by the input voltage and the load submitted. In this case, rectifier 1 consists only of a GRAETZ bridge and an inductive filter, whereas in rectifier 2, a three-phase step-down autotransformer is implemented to balance the voltages and allow the parallel connection between rectifiers 1 and rectifiers 2 .

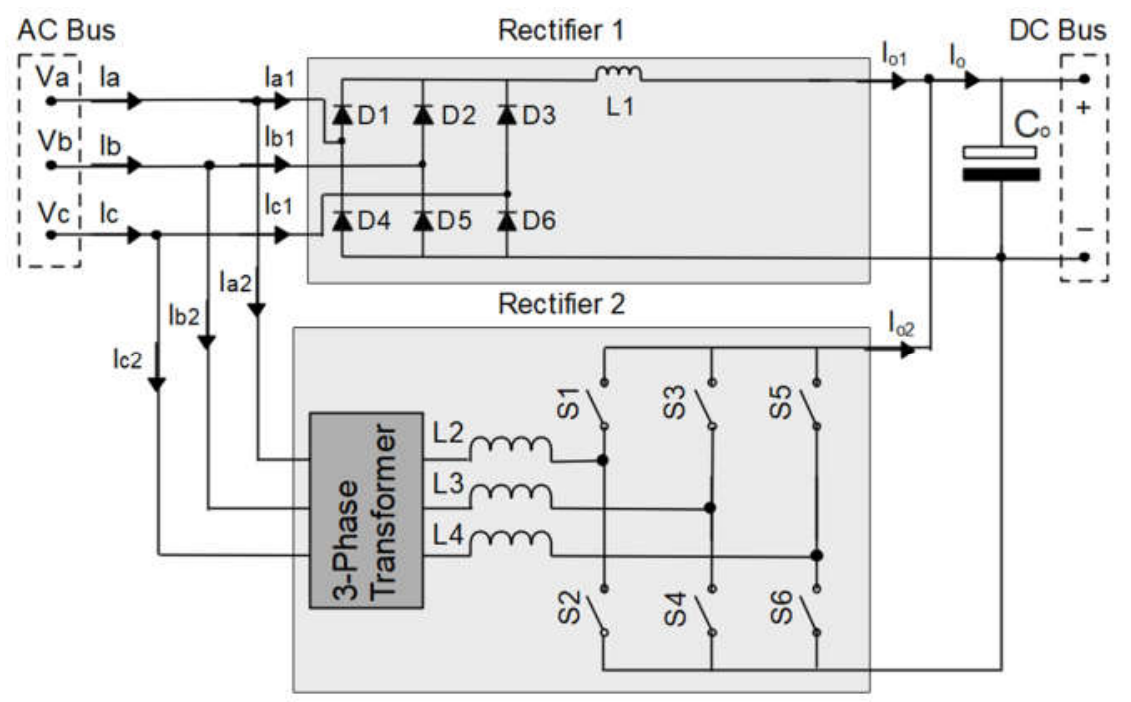

Figure 26. Configuration of the BHTR-R1//BR2 electrical circuit.

\subsection{Control Strategy Applied}

The control strategies analyzed are based on obtaining the signals that are sent to the current and voltage control loop. Voltage and current control loops consist of integrated circuits (analog) or digital signal processor circuits (digital). The working principle of controlling voltage and current loops has already been described in Section 3.2 for the converters BOOST, SEPIC, VIENNA and PWM BOOST. Therefore, the operation of the integrated circuits of the analog control and the programming or digital signal processor 
of the digital control will not be further investigated since this content is not part of the scope of this work.

Through the control strategy applied to the HTR, it can produce sinusoidal or multilevel input currents $[2,20,21]$, as shown in Table 6 . In the same Table 6, we can also notice that it is more common to develop HTR with sinusoidal input current.

Table 6. HTR type of control applied in HTR.

\begin{tabular}{|c|c|c|c|c|}
\hline HTR & Reference & Control & Circuit Employed & Current \\
\hline UHTR-BR1//BR2 & {$[2]$} & Analog & Blocks Circuit & Sinusoid \\
\hline \multirow{3}{*}{ UHTR-R1//BR2 } & [20] & Digital & - & Multilevel \\
\hline & [25] & Digital & Microcontroller & Sinusoid \\
\hline & [36] & Analog & IC, Analog Ports & Multilevel \\
\hline \multirow{2}{*}{ UHTR-BR1//SR2 } & [16] & Digital & DSP, TMS320F28335 & Sinusoid \\
\hline & [29] & Digital & DSP TMS320F2812 & Sinusoid \\
\hline \multirow{8}{*}{ UHTR-R1//SR2 } & [23] & Digital & FPGA, VHDL & Sinusoid \\
\hline & [28] & Digital & FPGA, VHDL & Sinusoid \\
\hline & [38] & Digital & DSP, TMS320F28335 & Sinusoid \\
\hline & [19] & Digital & DSP, TMS320F28335 & Sinusoid \\
\hline & [22] & Analog & Blocks Circuit & Multilevel \\
\hline & {$[14]$} & Analog & - & Multilevel \\
\hline & [12] & Analog & IC, Analog Ports & Multilevel \\
\hline & [30] & Digital & DSP, TMS320F28335 & Sinusoid \\
\hline \multirow{3}{*}{ UHTR-BR1//VR2 } & [21] & Analog & Blocks Circuit & Sinusoid \\
\hline & {$[6]$} & Analog & UC3854B & Sinusoid \\
\hline & [18] & Digital & - & Sinusoid \\
\hline \multirow{2}{*}{ UHTR-BR1//DR2 } & [13] & Digital & DSP & Sinusoid \\
\hline & [32] & Digital & DSP, TMS320F28335 & Sinusoid \\
\hline UHTR-BR1//StR2 & [17] & Digital & DSP, TMS320F2812 & Sinusoid \\
\hline \multirow{2}{*}{ BHTR-BR1//BR2 } & [26] & Analog & Blocks Circuit & Sinusoid \\
\hline & [34] & Digital & Mathematics & Sinusoid \\
\hline BHTR-R1//BR2 & [31] & Analog & Blocks Circuit & Sinusoid \\
\hline
\end{tabular}

For the sine wave, it is necessary that each HTR rectifier produces a different waveform, in such a way that when adding the two waveforms, a sinusoidal current form is obtained. For these forms of currents to be produced, an adequate control strategy is necessary. According to the literature search, the most common HTR control strategy to produce sinusoidal currents is shown in Figure 27. For the control system, current and voltage input signals are necessary for both rectifier 1 and rectifier 2 . Signal distributions are made in the current loop and the voltage loop of rectifier 1 and rectifier 2 [2,21,26,27]. These are distributed as follows:

For the current loop of rectifier 1, the current signal of the BOOST inductor $1\left(i_{L b}\right)$ is applied.

For the rectifier current loop 2 , the input current signals, $i_{a}, i_{b}, i_{c}$ and the reference voltage signals $v_{a}, v_{b}, v_{c}$ are applied.

The voltage loop is only one, and the error $\left(e_{v}\right)$ produced by the loop serves for the current loop of the two rectifiers.

The big secret of this strategy is to make the current control of rectifier 2 follow the same waveform as the input voltage (sinusoidal) through the signals $i_{a}, i_{b}, i_{c}$ and the reference voltage signals $v_{a}, v_{b}, v_{c}$. Therefore, the current from rectifier 2 will be a sinusoidal waveform minus the waveform from rectifier 1 . This subtraction occurs because the current signal sensor of rectifier 2 is placed at the input of the HTR. So, for 
rectifier 2, the sinusoidal current is following, but the value of the current is low in the periods when rectifier 1 is conducting current [2,21,26,27].

This control strategy is mostly used in analog control [2,6,21,26], but it can also be applied in digital control: just convert the analog signals into digital signals (using an analog/digital converter) and apply to a digital signal processor (DSP) with a suitable language, as was done in $[13,32]$ and is also applied in some varieties (with small changes in the control strategy, but the principle is the same) in $[16,19,29,30,38]$.

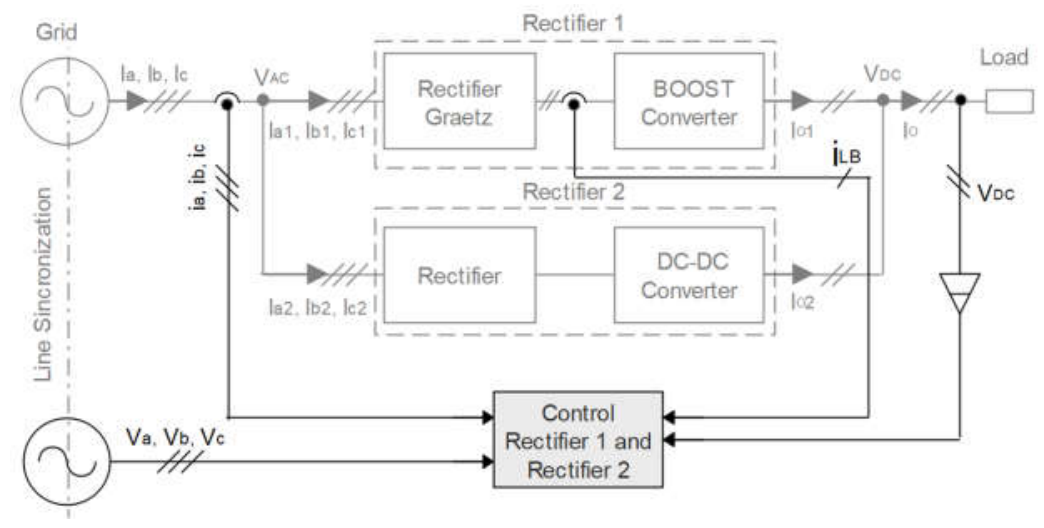

Figure 27. Configuration of electrical circuit applied in HTR with sinusoidal current.

For the multilevel waveform, it is necessary that each HTR rectifier produces a different waveform by adding the multilevel current form. According to the literature search, the strategy of the most common control system to produce multilevel currents is shown in Figure 28. The control system is carried out only on rectifier 2, and for that, only the reference voltage signals $\left(v_{a}, v_{b}, v_{c}\right)$, the input current signal of the converter $\left(i_{\text {conv }}.\right)$, and the output current signal of rectifier $1\left(I_{o 1}\right)$ are required.

First, the sinusoidal reference voltage signals $\left(v_{a}, v_{b}, v_{c}\right)$ are rectified and converted into a multilevel signal by the reference signal generator, as can be seen in Figure 28. Next, this multilevel signal (synchronized with the power grid) is applied to the control of rectifier 2, so that its input current follows the same shape, and for that, it also uses the input current signal of the converter $\left(i_{\text {conv }}\right)$. Note that the output current signal from rectifier $1\left(I_{o 1}\right)$ serves to be multiplied by the reference voltage signal to limit the current from rectifier 2 , and thus respect the current distribution limit between rectifier 1 and rectifier $2[12,14,20,22,36]$.

This control strategy is mostly used in analog control (applying an analog/digital converter and a digital signal processor, DSP) in $[12,14,22,36]$, but it can also be applied in digital control as in [20].

It is also important to note that this control strategy can also be applied to produce a sinusoidal current at the entrance to the HTR, as was done by a digital control in [25]. For this, it is enough to make the generator of the reference voltage signal produce an adequate signal, as shown in Figure 29.

Note that for digital control of the HTR, a digital signal processor (DSP) equipped with the Texas instrument TMS320F28335 is more employed, as can be seen in Table 6 . 


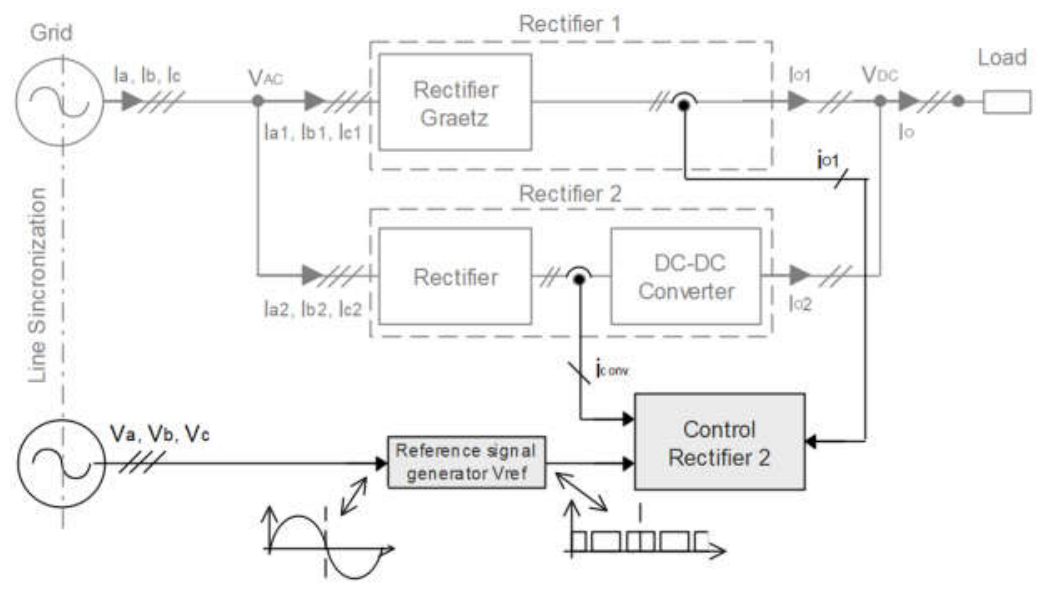

Figure 28. Configuration of electrical circuit applied in HTR with multilevel current.

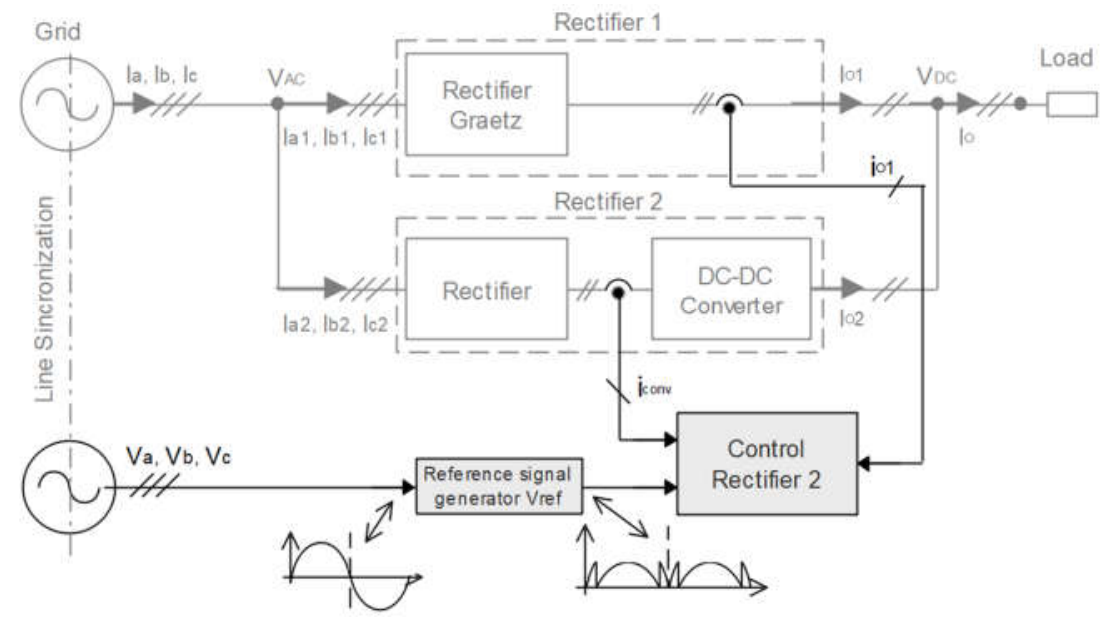

Figure 29. Configuration of electrical circuit applied in HTR with sinusoidal current, using a reference signal generator.

\subsection{PF and THD in HTR}

It is important that HTR be able to meet the standards of the international standards IEEE 519 and IEC6100-3-4 regarding the quality of electric power. These standards propose a high PF and a low THDi.

Thus, analyzing Table 7, it is noted that all HTR have a high PF, complying even with international standards. However, with respect to THDi, it varies according to the type of HTR, and the validation method employed (simulation or prototype).

In terms of simulation, three types of HTR comply with the rules, with UHTRBR1//BR2 studied in [2], UHTR-BR1//VR2 studied in [21], and BHTR-BR1//BR2 studied in [34].

In the case of the prototype, it can be seen in Table 7 that most of the HTR do not comply with international standards. However, it is important to note that some of the prototypes, specifically three types of HTR are interesting, as they present a high PF and a low THDi value, even complying with international standards, such as the UHTRBR1//SR2 studied in [16], the UHTR-R1//SR2 studied in $[19,28,38]$, and the UHTRBR1//StR2 studied in [17].

In summary, Table 7 shows that in terms of simulation, most HTRs can comply with international standards, but in terms of prototype, only the HTR that use the SEPIC converter and Star-switch in rectifier 2 comply with international standards. 
As already described, one of the objectives of an HTR is to make rectifier 1 (R1) process the largest possible portion of the rated power, since rectifier 1 is simpler, is more robust, and has few construction elements (indicating low financial cost). Therefore, it is important to analyze the power distribution among the HTR.

Table 7 shows a difference in the power distribution between the UHTR and the BHTR. The BHTR can achieve an unbalanced power distribution with $90 \% P_{o}$ on rectifier 1 and $10 \% P_{o}$ on rectifier 2, which corroborates with Formula (1), described in Section 3.2.

In the same analysis as in Table 7, the UHTR also show a difference in power distribution, when referring to the type of input current, sinusoidal or multilevel. Multilevel current rectifiers have an unbalanced power distribution, with $80 \% P_{o}$ to $84 \% P_{o}$ on rectifier $1(\mathrm{R} 1)$ and $20 \% P_{o}$ to $16 \% P_{o}$ on rectifier $2(\mathrm{R} 2)$; this is positive, since rectifier 1 is processing the largest portion of nominal power (about $80 \% P_{o}$ ), but it is not satisfactory, because it has a high THD value. The UHTR with sinusoidal current has a more balanced current distribution, reaching about $60 \% P_{o}$ to $52 \% P_{o}$ in rectifier 1 and $40 \% P_{o}$ to $48 \% P_{o}$ in rectifier 2 (which corroborates Formula (2), as described in Section 3.2), reaching high PF and low THD.

Table 7. PF and THD in HTR.

\begin{tabular}{|c|c|c|c|c|c|c|c|c|}
\hline HTR & Reference & e Validation & $P_{0}(k W)$ & $P_{0} R 1(\%) P$ & ${ }_{0} \mathrm{R} 2(\%)$ & PF (\%) & $\begin{array}{c}\text { THDi } \\
(\%)\end{array}$ & Current \\
\hline $\begin{array}{l}\text { UHTR- } \\
\text { BR1//BR2 }\end{array}$ & [2] & Simulation & 20 & 55.2 & 44.8 & 99.89 & 4.54 & Sinusoid \\
\hline \multirow{3}{*}{ UHTR-R1//BR2 } & [20] & Prototype & 6 & 80 & 20 & 97.7 & 13.18 & Multilevel \\
\hline & [25] & Prototype & 2.8 & 52 & 48 & - & - & Sinusoid \\
\hline & [36] & Prototype & 6 & 82 & 18 & 97.73 & 13.18 & Multilevel \\
\hline \multirow{2}{*}{$\begin{array}{l}\text { UHTR- } \\
\text { BR1//SR2 }\end{array}$} & [16] & Prototype & 5 & 60 & 40 & 98 & 3.753 & Sinusoid \\
\hline & [29] & Simulation & 5 & 60 & 40 & - & - & Sinusoid \\
\hline \multirow{8}{*}{ UHTR-R1//SR2 } & [23] & Prototype & 1.74 & - & - & 99 & 6.3 & Sinusoid \\
\hline & [28] & Prototype & 1 & - & - & 98 & 4.1 & Sinusoid \\
\hline & [38] & Prototype & 5 & 60 & 40 & - & 1.95 & Sinusoid \\
\hline & [19] & Prototype & 5 & 60 & 40 & - & 3.75 & Sinusoid \\
\hline & [22] & Simulation & 3 & 80 & 20 & - & 13.7 & Multilevel \\
\hline & [14] & Prototype & 3 & 79 & 21 & 98.9 & 14.7 & Multilevel \\
\hline & [12] & Prototype & 6 & 84 & 16 & 98 & 12.5 & Multilevel \\
\hline & [30] & Prototype & 5 & 60 & 40 & - & 1.95 & Sinusoid \\
\hline \multirow{3}{*}{$\begin{array}{l}\text { UHTR- } \\
\text { BR1//VR2 }\end{array}$} & [21] & Simulation & 20 & 55.2 & 44.8 & - & 3.22 & Sinusoid \\
\hline & {$[6]$} & Prototype & 21 & 55.2 & 44.8 & 98.89 & 7.9 & Sinusoid \\
\hline & [18] & Prototype & 5 & 50 & 50 & - & 3 & Sinusoid \\
\hline \multirow{2}{*}{$\begin{array}{c}\text { UHTR- } \\
\text { BR1//DR2 }\end{array}$} & [13] & Prototype & 5 & 59 & 41 & 99 & 5.1 & Sinusoid \\
\hline & [32] & Prototype & 5 & - & - & - & 7 & Sinusoid \\
\hline $\begin{array}{c}\text { UHTR- } \\
\text { BR1//StR2 }\end{array}$ & [17] & Prototype & 18 & 55 & 45 & - & 3.9 & Sinusoid \\
\hline \multirow{2}{*}{$\begin{array}{c}\text { BHTR- } \\
\text { BR1//BR2 }\end{array}$} & [26] & Simulation & 20 & 90 & 10 & - & & Sinusoid \\
\hline & [34] & Simulation & 10 & - & - & - & 2.01 & Sinusoid \\
\hline BHTR-R1//BR2 & [31] & Simulation & 2.4 & - & - & - & 5.95 & Sinusoid \\
\hline
\end{tabular}

\subsection{Applications}

In the research of the studied literature, there were only three specific applications that used the HTR, since other studies develop the HTR to meet some load requirements, and others present only some application proposals. 
In the specific applications of the HTR, a prototype of a three-phase fast charger for off-board electric vehicles (EV) of $7.5 \mathrm{~kW}$ [39] was developed. The development of this fast charger was based on UHTR-R1//SR2 followed by an interleaved BUCK converter (DC/DC stage). In this charger, UHTR-R1//SR2 has the function of converting AC to DC with active correction of the power factor to obtain a sinusoidal current at the input of the charger with low THDi value, high PF, as well as good efficiency and a reduced financial cost, since the implemented HTR is composed of a GRAETZ bridge (simple, robust, and with low financial cost) in parallel with a modular three-phase rectifier from the SEPIC converter. The interleaved BUCK converter is controlled by PWM, allowing constant current [39].

In [25], an HTR is applied to power a microgrid DC system. This system is composed of a set of energy sources connected to the DC bus, such as photovoltaic (PV) energy, wind turbine, and the electrical network through the HTR. It can be said that this converter is based on BHTR-R1//BR2, but logically with some changes so that it can be applied to a microgrid DC. The converter consists of a three-phase GRAETZ bridge rectifier (with an inductive filter at the input of each phase) connected in parallel with a three-phase PWM BOOST rectifier associated in series by an isolation system. The purpose of the rectifier is to supply energy to the DC bus of the microgrid system and to control (or stabilize) the voltage of the DC bus by means of the control on rectifier 2. It is also a high-density rectifier of power that can provide high power factor correction and low current harmonic distortion. Thus, the implemented HTR maintains sinusoidal currents at the input with high PF and low THD, providing the DC bus with a constant voltage of $400 \mathrm{~V}$ [25].

Another proven application of the HTR is in driving an induction motor using a system with rectifier and hybrid inverter. The hybrid inverter is given per cell, and the objective is to implement one cell in each phase, so the hybrid converter is composed of three cells. Each cell consists of a hybrid rectifier and a balance inverter [10,15].

As already mentioned, in some studies, they develop the HTR to meet some load requirements, and others present only some application proposals, which will be described below.

Another interesting application is to develop the HTR to supply a pulsating lowfrequency charge such as a beacon. These loads (headlamp) cause high current pulses with low frequency, which can cause damage to the power supply. The HTR developed in $[11,35]$ to feed pulsating loads is based on BHTR-R1//BR2. It consists of the GRAETZ bridge rectifier 1 and the rectifier 2 consisting of two stages, being a three-phase PWM rectifier of the BOOST type (first stage), which is associated in series with a converter BUCK (second stage). In this way, rectifier 1 is used only for stable energy transmission, while rectifier 2 is used for the pulsation part. Obviously, the input power of rectifier 2 (first stage) is constant, and the second stage is pulsating to satisfy the load's pulses. Thus, the constant power output of the AC source is satisfied [11,35].

In other works, an HTR is developed to solve the problem of temporary voltage sags in automated systems using speed drives (ASDs): UHTR-BR1//SR2 [16,29,30].

The HTR is also proposed to be used as part of an electric motor drive system by means of an HTR that produces a DC, and then, a frequency converter (inverter) is connected in order to obtain an AC bus where the electric motors will be connected, thus allowing an adequate control of the motors [25].

\section{Discussion}

The hybrid three-phase rectifier (HTR) is a rectifier composed normally of two rectifiers in parallel, each producing a different form of input current and contributing to the total output power. The result is an input current of the HTR of sinusoidal or multilevel waveform. In this case, the HTR consists of rectifier 1 in parallel with rectifier 2. Rectifier 1 is a GRAETZ bridge rectifier that can be combined with a BOOST converter to control the output voltage. Rectifier 2, on the other hand, is a rectifier with an active 
correction of the power factor, and it can be of BOOST, SEPIC, VIENNA, or PWM BOOSTtype topology. The different types of HTR are named and listed in Table 5.

Figure 3 shows the distribution of the articles by the year of its publication. In total, 34 papers were published in the annual survey from 1999 to 2020. There is a notable lack of published papers on HTR, observing that during some years (6 years), no articles have been published. Among the published articles, it can be noted (analyzing the Table 1) that about $29.41 \%$ of the articles were published in journals and $70.59 \%$ were published in conferences. It is a reasonable difference. The difference is explained by the fact that to build an HTR prototype, it is more difficult to build than a classical rectifier, and most of the journals only accept articles with experimental results and analysis of a prototype. It is normal to publish more articles in conference proceedings than in journals. This is especially true for the high-quality (e.g., IEEE) journals. It should also be noted that apparently, the country that leads with the most conference papers published on this technology is Brazil. It is a bit strange to state this by analyzing only the number of articles published per author and his affiliation but considering that five of the 10 papers published in journals are written also by Brazilian authors, the conclusion is the same.

The analysis of the HTR operation in all different cases shows that the output voltage can be controlled or not. This depends on the structure of the HTR, and it depends specifically on the chosen rectifier 1 . When the GRAETZ bridge of rectifier 1 is associated with a BOOST converter, it is possible to control the output voltage. If rectifier 1 has only the GRAETZ bridge, it will not be possible to control the output voltage [2,21]. At first, it can be concluded that the structure of the HTR with output voltage control is the most interesting, since it allows supplying a large variation of the load and a variety of voltage required by the load. That means that through the control, it is possible to select an output voltage suitable for the load (without changing the input voltage) while keeping the output voltage stable, even under load variation or input voltage variation. In the structure without the control of the output voltage, it is more difficult to adapt the operation to the load requirement. This is because the output voltage of the HTR is limited to the peak of the input voltage, and the variation of the load can affect the operation of the HTR.

Among the types of controls applied to the HTR, we analyzed the situation and concluded that the best way to carry out the control strategy is the one represented in Figure 27. This solution is preferred because it is easier to obtain a sinusoidal reference voltage for rectifier 2 (from a sample of the voltage input). This is more difficult for the other control strategies based on implementing a circuit that generates the reference voltage of rectifier 2, since this reference voltage has a different shape from the input voltage of the HTR. A comparison between the two types of control, digital or analogue, shows that there is not much difference in the final operation results of the HTR. Anyway, if the future development of the technology is considered, the digital control allows easily adding more functionalities, e.g., meeting the requirements of some loads, into the HTR. It may be concluded that the digital control seems to be the best option for the future. In the case of analog control, implementations based on the popular IC UC3854 are more widely seen, whereas Table 6 in the digital control indicates that it is more usual to use the digital signal processor (DSP) equipped with the Texas Instrument TMS320F28335.

Considering the input current waveform of the UHTR, i.e., whether is it sinusoidal or multilevel, it is noted that UHTRs with multipulse input currents seem to be more interesting only at high power levels, since the THDi obtained will be around $13 \%$. This higher value of THDi is not good, as the international standards IEEE Std 519-2014 indicate a THDi of less than $5 \%$ for the lower power levels. In the case of the UHTR with sinusoidal input currents, they seem interesting at lower power levels, since some of the proposed structures can comply with the international standards. This is specifically true for the structure of the UHTR, considering only the prototypes with an SEPIC converter and Star-switch on rectifier 2 (UHTR-BR1//SR2, UHTR-R1//SR2, UHT, UHTR-BR1//StR2) $[16,17,19,28,38]$, according to Table 7 . 
One of the objectives of the HTR is to make rectifier 2 process the largest possible portion of the nominal power (given the advantages of rectifier 1, being simple, robust, and reliable) $[2,20,21]$. It is also noted that in the UHTR, the greater the power processed by rectifier 1 , the greater the THDi. Therefore, to comply with international standards and allow rectifier 1 to process the largest portion of nominal power, the ideal should be that the power distribution in the UHTR is around $55 \% P_{o}$ in rectifier 1 and $45 \% P_{o}$ in rectifier 2. In the case of the bidirectional three-phase hybrid rectifier (BHTR), it can function correctly (complying with the standards) with the same power distribution $\left(55 \% P_{o}\right.$ on rectifier 1 and $45 \% P_{o}$ on rectifier 2), but taking into account the possibility that rectifier 1 basically may process all the power and rectifier 2 processes only the energy portions necessary to achieve a high power factor and low THDi at the input, it is also very interesting and possible to make the power distribution $90 \% P_{o}$ on rectifier 1 and $10 \% P_{o}$ on rectifier 2 [21], thus making it a very interesting structure.

Considering the applications of the HTR, the literature presents few studies, but some of the interesting applications presented are the use of HTR in a fast charger for electric vehicles and in a microgrid DC [25,39]. These are interesting application areas being constantly developing. Many companies are interested in improving the electric vehicle charging system and the DC microgrids power supply. It must be noted that the application of the HTR in those areas may have advantages because the HTR uses the GRAETZ bridge rectifier (rectifier 1), which is a simple, robust, and reliable structure that can present a low financial cost, in combination with the other structure, rectifier 2, which allows the HTR to achieve a sinusoidal input current with low THDi and high PF.

\section{Recommendations}

The development of HTR with a BOOST converter in rectifier 2 (UHTR-BR1//BR2) without the use of an isolation transformer was only possible in 2019. This was possible because the author replaced the inductor of the BOOST converter by a coupled inductor to mitigate the current interactions [2]. It must be considered an innovation. It was only proposed by simulation at that time, but the researchers prepared a prototype for the complete experiment to validate that HTR proposal.

Analyzing the structure of an HTR, it can be built with a GRAETZ bridge on rectifier 1 , and on rectifier 2, an autotransformer is applied to lower the voltage (to an appropriate level) and allow connection in parallel. This is proposed by BHTR-R1//BR2. Following the same logic, it is possible, and it is recommended in this paper, to develop the following structures (these are not found in the literature):

First unidirectional three-phase hybrid rectifier with rectifier 1 and VIENNA converter on rectifier 2 with transformer (UHTR-R1//VR2).

Second unidirectional three-phase hybrid rectifier with rectifier 1 and Delta-Switch converter on rectifier 2 with transformer (UHTR-R1//DR2).

Third unidirectional three-phase hybrid rectifier with rectifier 1 and Star-switch converter on rectifier 2 with transformer (UHTR-R1//StR2).

\section{Conclusions}

The studies reviewed in this paper provided a comprehensive view of the threephase hybrid (HTR) rectifiers. These consist of rectifier 1 (made as a GRAETZ bridge, in some cases associated with a BOOST converter) and rectifier 2 (a rectifier with BOOST converter, SEPIC, VIENNA rectifier, or even a BOOST type PWM can be used). With this variation of converters that can be used in rectifier 2, it has been possible to find about nine types of HTR in the literature. According to the small number of papers found after a deep search in the literature, there seems to exist little interest on the part of researchers to publish articles on HTR. Among the structures of the HTR with the prototype developed and described, which presented good results, referring to high PF and low THDi, the structures that use the SEPIC and VIENNA converters in rectifier 2 (UHTRBR1//SR2, UHTR-R1//SR2, UHTR-BR1//VR2) were showing best results. 
It is verified that as the power processed in rectifier 1 of the UHTR increases, the THDi also increases. Therefore, the best way to distribute power is to assign $55 \%$ of the rated power to rectifier 1 . In the case of BHTR, rectifier 1 can process $90 \%$ of the rated power. Analyzing the operation of the HTR, it proves to be a viable solution for many low-power applications, but the literature presents few studies.

In general, the HTR is very interesting because it allows combining the advantages of a GRAETZ bridge rectifier with the advantages of a rectifier with an active power factor correction.

Author Contributions: Protocol development, string creation, paper reading and data extraction, data interpretation and document writing: J.T.G.; Protocol validation, string creation, data validation, document writing, supervision: S.V.; String validation, data extraction, document writing, supervision: R.M. String validation, paper reading and data extraction: A.G. Protocol validation, string validation, and data validation: F.B. The other parameters were made by the authors in a mutual way. All authors have read and agreed to the published version of the manuscript."

Funding: This research received no external funding.

Acknowledgments: Portuguese Foundation for Science and Technology (FCT) and CTS, project UIDB/00066/2020.

Conflicts of Interest: The authors declare no conflict of interest.

\section{References}

1. Kumar, D.; Zare, F.; Ghosh, A. DC microgrid technology: System architectures, AC grid interfaces, grounding schemes, power quality, communication networks, applications, and standardizations aspects. IEEE Access 2017, 5, 12230-12256.

2. Gonçalves, J.T.; Valtchev, S.; Melicio, R.; Al-Saadi, M. Three-phase unidirectional transformerless hybrid rectifier with BOOST converter. In Proceedings of the IEEE 1st Global Power, Energy and Communication Conference (GPECOM), Nevsehir, Turkey, 12-15 June 2019; pp. 158-163.

3. Gonçalves, J.T.; Valtchev, S.; Melicio, R. Current Interactions Mitigation in 3-Phase PFC Modular Rectifier through DifferentialMode Choke Filter BOOST Converter. Appl. Sci. 2021, 11, 1684.

4. Siebert, A.; Troedson, A.; Ebner, S. AC to DC power conversion now and in the future. IEEE Trans. Ind. Appl. 2002, 38, 934-940.

5. Kolar, J.W.; Ertl, H. Status of the techniques of three-phase rectifier systems with low effects on the mains. In Proceedings of the 21st International Telecommunications Energy Conference (INTELEC'99), Copenhagen, Denmark, 9 June 1999 ; p. 279.

6. Alves, R.L.; Barbi, I. Analysis and implementation of a hybrid high-power-factor three-phase unidirectional rectifier. IEEE Trans. Power Electron. 2009, 24, 632-640.

7. Tangtheerajaroonwong, W.; Hatada, T.; Wada, K.; Akagi, H. Design of a transformerless shunt hybrid filter integrated into a three-phase diode rectifier. In Proceedings of the 37th IEEE Power Electronics Specialists Conference, Jeju, Korea, 18-22 June 2006; pp. 1-7.

8. Kitchenham, B.; Brereton, O.P.; Budgen, D.; Turner, M.; Bailey, J.; Linkman, S. Systematic literature reviews in software engineering-a systematic literature review. Inf. Softw. Technol. 2009, 51, 7-15.

9. Kitchenham, B. Guidelines for Performing Systematic Literature Reviews in Software Engineering; Version 2.3, EBSE Technical Report; Keele University: Keele, UK; University of Durham: Durham, UK, 2007.

10. Manjrekar, M.D.; Steimer, P.K.; Lipo, T.A. Hybrid multilevel power conversion system: a competitive solution for high power applications. Conference Record of the 1999 IEEE Industry Applications Conference. Thirty-Fourth IAS Annual Meeting (Cat. No.99CH36370), Phoenix, AZ, USA, 3-7 Oct. 1999; pp. 1520-1527.

11. Zhu, J.; Wu, H.; Chen, J.; Li, L.; Hua, M.; Xing, Y. A Hybrid Three-Phase AC/DC Power System for Low-Frequency Pulsed Load Applications. IEEE Trans. Ind. Electron. 2020, 68, 1871-1882.

12. De Freitas, L.C.G.; Simões, M.G.; Canesin, C.A.; de Freitas, L.C. Performance evaluation of a novel hybrid multipulse rectifier for utility interface of power electronic converters. IEEE Trans. Ind. Electron. 2007, 54, 3030-3041.

13. Soeiro, T.B.; Kolar, J.W. Analysis of high-efficiency three-phase two-and three-level unidirectional hybrid rectifiers. IEEE Trans. Ind. Electron. 2012, 60, 3589-3601.

14. De Freitas, L.G.; Simões, M.G.; Canesin, C.A.; de Freitas, L.C. Programmable PFC based hybrid multipulse power rectifier for ultra clean power application. IEEE Trans. Power Electron. 2006, 21, 959-966.

15. Manjrekar, M.D.; Steimer, P.K.; Lipo, T.A. Hybrid multilevel power conversion system: A competitive solution for high-power applications. IEEE Trans. Ind. Appl. 2000, 36, 834-841.

16. Costa, A.V.; Rodrigues, D.B.; de Lima, G.B.; de Freitas, L.C.; Coelho, E.A.A.; Farias, V.J.; Freitas, L.C.G. New hybrid high-power rectifier with reduced THDI and voltage-sag ride-through capability using BOOST converter. IEEE Trans. Ind. Appl. 2013, 49, 2421-2436. 
17. Song, W.Z.; Dai, Z.H.; Xie, N.; Wang, Y.Y.; Wheeler, P. Two methods for controlling three-time fundamental frequency neutralpoint voltage oscillation in a hybrid VIENNA rectifier. IET Power Electron. 2019, 12, 932-943.

18. Li, J.; Wang, M.; Zhao, Y.; Wang, J.; Yang, D.; Li, X. Passivity-based control of the hybrid rectifier for medium and high-power application. IET Power Electron. 2019, 12, 4070-4078.

19. Rodrigues, D.B.; Costa, A.V.; Lima, G.B.; de Freitas, L.C.; Coelho, E.A.; Farias, V.J.; Freitas, L.C. DSP-based implementation of control strategy for sinusoidal input line current imposition for a hybrid three-phase rectifier. IEEE Trans. Ind. Inform. 2012, 9, 1947-1963.

20. De Freitas, L.G.; Coelho, E.A.A.; Finazzi, A.P.; Simoes, M.G.; Canesin, C.A.; De Freitas, L.C. Programmable PFC based hybrid multipulse power rectifier for utility interface of power electronic converters. In Proceedings of the IEEE 36th Power Electronics Specialists Conference, Dresden, Germany, 16 June 2005; pp. 2237-2243.

21. Alves, R.L.; Font, C.I.; Barbi, I. A novel unidirectional hybrid three-phase rectifier system employing BOOST topology. In Proceedings of the 2005 IEEE 36th Power Electronics Specialists Conference, Dresden, Germany, 16 June 2005; pp. 487-493.

22. De Freitas, L.G.; Simões, M.G.; Canesin, C.A.; De Freitas, L.C. A novel programmable PFC based hybrid rectifier for ultra clean power application. In Proceedings of the IEEE 35th Annual Power Electronics Specialists Conference, Aachen, Germany, 20-25 June 2004; pp. 2172-2177.

23. Soares, J.D.O.; Canesin, C.A.; de Freitas, L.C. A true programmable HPF hybrid three-phase rectifier. In Proceedings of the IEEE Power Electronics Specialists Conference, Rhodes, Greece, 15-19 June 2008; pp. 3843-3849.

24. Rodrigues, D.B.; Silva, P.R.; Lima, G.B.; Coelho, E.A.; Freitas, L.C. Grid connected dc distribution network deploying high power density rectifier for dc voltage stabilization. In Proceedings of the IEEE Applied Power Electronics Conference and Exposition (APEC), Long Beach, CA, USA, 20-24 March 2016; pp. 3585-3590.

25. De Freitas, L.G.; Vincenzi, F.; Freitas, M.A.A.; Fernandes, E.R.; Mendonça, R.G.; de Freitas, L.C. Programmable PFC based hybrid multipulse power rectifier with sinusoidal input line current imposed by digital controller. In Proceedings of the APEC 07-Twenty-Second Annual IEEE Applied Power Electronics Conference and Exposition, Anaheim, CA, USA, 25 February-1 March 2007; pp. 1356-1361.

26. Font, C.I.; Barbi, I. A new high power factor bidirectional hybrid three-phase rectifier. In Proceedings of the Twenty-First Annual IEEE Applied Power Electronics Conference and Exposition (APEC), Dallas, TX, USA, 19-23 March 2006; pp. 10482334.

27. Alves, R.L.; Barbi, I. A new hybrid high power factor three-phase unidirectional rectifier. In Proceedings of the IEEE International Symposium on Industrial Electronics, Montreal, QC, Canada, 9-13 July 2006; pp. 1046-1051.

28. Soares, J.O.; Canesin, C.A.; De Freitas, L.C. Hybrid three-phase hpf rectifier with programmable input current THD, using FPGA device and VHDL language. In 7th International Conference on Power Electronics, Daegu, Korea, 22-26 October 2007; pp. 420-425.

29. Costa, A.V.; Rodrigues, D.B.; de Freitas, L.C.; Vieira, J.B.; Coelho, E.A.A.; Farias, V.J.; Freitas, L.C. Hybrid high-power rectifier with reduced THDI and voltage sag ride-through capability. In Proceedings of the IEEE Industry Applications Society Annual Meeting, Orlando, FL, USA, 9-13 October 2011; pp. 1-6.

30. Costa, A.V.; Rodrigues, D.B.; Lima, G.B.; de Freitas, L.C.; Coelho, E.A.; Farias, V.J.; Freitas, L.C. Retrofitting technique to improve voltage sags ride-through capability of ASD using SEPIC rectifiers. In Proceedings of the Twenty-Seventh Annual IEEE Applied Power Electronics Conference and Exposition (APEC), Orlando, FL, USA, 5-9 February 2012; pp. 1469-1476.

31. Bai, L.; Wang, D.; Zhou, Y. Study on the current control strategy of hybrid rectifier based on the PR controller. In Proceedings of the International Conference on Electrical Machines and Systems (ICEMS), Busan, Korea, 26-29 October 2013; pp. 1693-1696.

32. Gedroyc, K.; Jasinski, M. All-SiC $5 \mathrm{~kW} / 50 \mathrm{kHz}$ three-phase hybrid rectifier with reduced input current harmonics. In Proceedings of the 19th European Conference on Power Electronics and Applications (EPE'17 ECCE Europe), Warsaw, Poland, 11-14 September 2017; p. 1.

33. Yuanpeng, F.; Jiuhe, W.; Jianguo, L.; Xiaobin, M. Research of hybrid rectifier with LCL filter. In Proceedings of the 2018 IEEE International Conference of Safety Produce Informatization (IICSPI), Chongqing, China, 10-12 December 2018; pp. 575-581.

34. Jiang, Y.; Wang, J.; Li, Q.; Feng, Y.; Mu, X. The passivity-based hybrid control of NPC hybrid three phase voltage source rectifier. In Proceedings of the IEEE International Power Electronics and Application Conference and Exposition (PEAC), Shenzhen, China, 4-7 November 2018; pp. 1-6.

35. Chen, J.; Wu, H.; Zhu, J.; Li, L.; Xing, Y. A Three-Phase AC/DC Power System with Paralleled Active and Passive Rectifiers for Low-Frequency Pulsed Load Applications. In Proceedings of the IEEE 9th International Power Electronics and Motion Control Conference (IPEMC2020-ECCE Asia, Nanjing, China, 29 November-2 December 2020; pp. 1595-1599.

36. De Freitas, L.G.; Coelho, E.A.; Parreira, E.F.; Oliveira, M.A.; de Freitas, L.C. Multipulse power rectifier without using multiphase transformers. In Proceedings of the 31st Annual Conference of IEEE Industrial Electronics Society (IECON), Raleigh, NC, USA, 6-10 November 2005; p. 6.

37. Rajan, G.S.; Rajan, C.C.A. Input stage improved power factor of three phase diode rectifier using hybrid unidirectional rectifier. In Proceedings of the International Conference on Nanoscience, Engineering and Technology (ICONSET 2011), Chennai, India, 28-30 November 2011; pp. 589-592.

38. Costa, A.V.; Rodrigues, D.B.; de Freitas, L.C.; Vieira, J.B.; Coelho, E.A.; Farias, V.J.; Freitas, L.C. Hybrid three-phase rectifier with high power factor and voltage sags ride-through capability for utility interface of adjustable speed drives. In Proceedings of the XI Brazilian Power Electronics Conference, Natal, Brazil, 11-15 September 2011; pp. 582-588. 
39. Suarez, C.A.; Melo, G.A.; Canesin, C.A. A 7.5 kW Off-board Three-Phase Fast Charger Prototype for Electric Vehicles. In Proceedings of the 20th European Conference on Power Electronics and Applications (EPE ECCE Europe), Riga, Latvia, 17-21 September 2018; p. 1.

40. Soeiro, T.B.; Friedli, T.; Hartmann, M.; Kolar, J.W. New unidirectional hybrid delta-switch rectifier. In Proceedings of the 37th Annual Conference of the IEEE Industrial Electronics Society (IECON), Melbourne, VIC, Australia, 7-10 November 2011; pp. 1474-1479.

41. Song, W.Z.; Xie, N.; Wang, Y.Y.; Dai, Z.H.; Pat, W. Two methods to control neutral-point voltage fluctuation for a hybrid VIENNA rectifier. J. Eng. 2018, 13, 654-660. 